University of Tennessee Health Science Center

UTHSC Digital Commons

\title{
$5-2011$
}

\section{Eccentric Interchangeability of the Semi-Adjustable Articulator: A Pilot Study}

Mark James Hopkins

University of Tennessee Health Science Center

Follow this and additional works at: https://dc.uthsc.edu/dissertations

Part of the Prosthodontics and Prosthodontology Commons

\section{Recommended Citation}

Hopkins, Mark James, "Eccentric Interchangeability of the Semi-Adjustable Articulator: A Pilot Study" (2011). Theses and Dissertations (ETD). Paper 122. http://dx.doi.org/10.21007/etd.cghs.2011.0141.

This Thesis is brought to you for free and open access by the College of Graduate Health Sciences at UTHSC Digital Commons. It has been accepted for inclusion in Theses and Dissertations (ETD) by an authorized administrator of UTHSC Digital Commons. For more information, please contact jwelch30@uthsc.edu. 


\title{
Eccentric Interchangeability of the Semi-Adjustable Articulator: A Pilot Study
}

\begin{abstract}
Background: Dental articulation is a method of approximating the patient's mandibular motion in order to allow for analysis of dental relations and fabrication of appliances. The most prevalent method used in teaching institutions is the semi-adjustable articulator. Several of these instruments claim interchangeability without loss of clinical accuracy and studies have supported this claim. No studies to date have assessed the interchangeability of the articulators in any relation other than hinge axis closure. Assessment of the accuracy of interchangeability of calibrated articulators will inform the profession of this parameter of articulation and allow for informed decisions on whether or not to rely on interchangeability in analysis and fabrication.
\end{abstract}

Objectives: To examine the ability of an operator to set condylar inclination repeatedly on a semiadjustable articulator. To assess the utility of a new measurement jig to assess the calibration status of articulators and to measure sample of instruments repeatability in hinge axis closure and then in measured lateral excursion to assess eccentric interchangeability.

Method: 78 Unused Whip Mix 2240 and 71, 1 year-old Whip Mix 2240 semi-adjustable articulators were placed in a custom made measurement jig following calibration. Condylar inclination was evaluated with a digital angle meter and gauge blocks were utilized as reference points to measure the position ( $X$ and $Y$ axes) of the test gauge and a height meter was used to measure the vertical ( $Z$ axis) in hinge axis closure position and in a measured lateral excursion.

Results: The data suggests that: (1) A single operator was able to program the horizontal condylar inclination of the Whip Mix 2240 with 95\% confidence within one degree of his target value. (2) A prescribed lateral movement on a series of new articulators was able to position a specific measurement point (maxillary first bicuspid facial cusp tip) in the same spatial location within tolerance reported for hinge axis closure of calibrated instruments. (3) A prescribed lateral movement on a series of used articulators positions a specific measurement point (maxillary first bicuspid facial cusp tip) in the same spatial location within tolerance reported for hinge axis closure of calibrated instruments (4) $88.5 \%$ of 1 year-old instruments verified as interchangeable with the 2245 check gauge. (5) A calibrated Whip Mix 2240 can be eccentrically positioned with $95 \%$ confidence within $+/-0.2 \mathrm{~mm}$ vertically and $+/-0.1 \mathrm{~mm}$ horizontally.

\section{Document Type}

Thesis

Degree Name

Master of Dental Science (MDS)

\section{Program}

Prosthodontics

\section{Research Advisor}

David R. Cagna, D.M.D., M.S.

\section{Keywords}

Articulator, Interchangeability, Calibration, Eccentric, Excursion, Tolerance 


\section{Subject Categories}

Dentistry | Medicine and Health Sciences | Prosthodontics and Prosthodontology 
Eccentric Interchangeability of the Semi-Adjustable Articulator: A Pilot Study

\author{
A Thesis \\ Presented for \\ The Graduate Studies Council \\ The University of Tennessee \\ Health Science Center
}

\author{
In Partial Fulfillment \\ Of the Requirements for the Degree \\ Master of Dental Science \\ From The University of Tennessee
}

\author{
By \\ Mark James Hopkins \\ May 2011
}


Copyright (C) 2011 by Mark J. Hopkins.

All rights reserved. 


\section{ACKNOWLEDGEMENTS}

I would like to express my gratitude to everyone who has helped me in my endeavor of pursuing a Master of Dental Science in Prosthodontics. I am grateful to Dr. David Cagna, who has been my mentor and advisor in this project. I would also like to thank my committee members, Dr. Vinay Jain, Dr. Swati Ahuja, Dr. Robert Brandt and Mark Scarbecz for their advice and experience. I would also like to extend my special thanks to Whip Mix Corporation especially Lori Gottschlich for coordination, and Mike Lade for his technical assistance and the CAD drawings used to illustrate the project. To my wife Colette, and children Torsten and Linnea, you are the most important part of life, I love you. 


\begin{abstract}
Background: Dental articulation is a method of approximating the patient's mandibular motion in order to allow for analysis of dental relations and fabrication of appliances. The most prevalent method used in teaching institutions is the semi-adjustable articulator. Several of these instruments claim interchangeability without loss of clinical accuracy and studies have supported this claim. No studies to date have assessed the interchangeability of the articulators in any relation other than hinge axis closure.

Assessment of the accuracy of interchangeability of calibrated articulators will inform the profession of this parameter of articulation and allow for informed decisions on whether or not to rely on interchangeability in analysis and fabrication.
\end{abstract}

Objectives: To examine the ability of an operator to set condylar inclination repeatedly on a semi-adjustable articulator. To assess the utility of a new measurement jig to assess the calibration status of articulators and to measure sample of instruments repeatability in hinge axis closure and then in measured lateral excursion to assess eccentric interchangeability.

Method: 78 Unused Whip Mix 2240 and 71, 1 year-old Whip Mix 2240 semi-adjustable articulators were placed in a custom made measurement jig following calibration. Condylar inclination was evaluated with a digital angle meter and gauge blocks were utilized as reference points to measure the position ( $\mathrm{X}$ and $\mathrm{Y}$ axes) of the test gauge and a height meter was used to measure the vertical ( $\mathrm{Z}$ axis) in hinge axis closure position and in a measured lateral excursion.

Results: The data suggests that: (1) A single operator was able to program the horizontal condylar inclination of the Whip Mix 2240 with 95\% confidence within one degree of his target value. (2) A prescribed lateral movement on a series of new articulators was able to position a specific measurement point (maxillary first bicuspid facial cusp tip) in the same spatial location within tolerance reported for hinge axis closure of calibrated instruments. (3) A prescribed lateral movement on a series of used articulators positions a specific measurement point (maxillary first bicuspid facial cusp tip) in the same spatial location within tolerance reported for hinge axis closure of calibrated instruments (4) $88.5 \%$ of 1 year-old instruments verified as interchangeable with the 2245 check gauge. (5) A calibrated Whip Mix 2240 can be eccentrically positioned with 95\% confidence within $+/-0.2 \mathrm{~mm}$ vertically and $+/-0.1 \mathrm{~mm}$ horizontally. 


\section{TABLE OF CONTENTS}

CHAPTER 1: INTRODUCTION AND BACKGROUND ….............................. 1

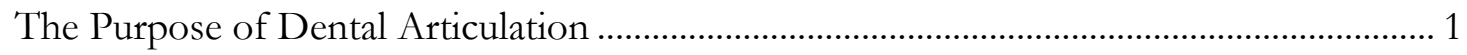

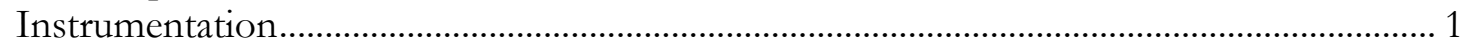

Recommended Instrumentation from American Dental Schools .......................................... 2

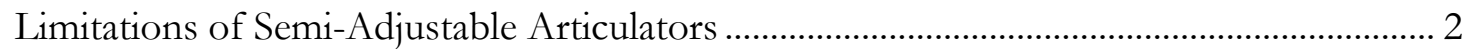

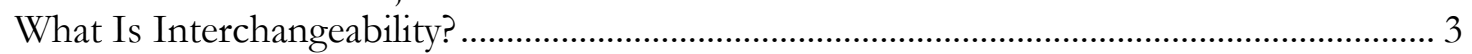

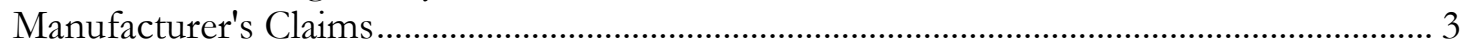

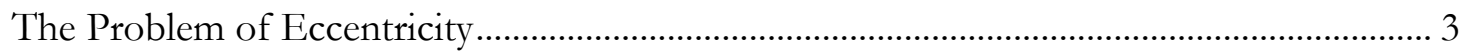

CHAPTER 2: REVIEW OF LITERATURE................................................5

Hinge Axis Closure and Interchangeability ……................................................................. 5

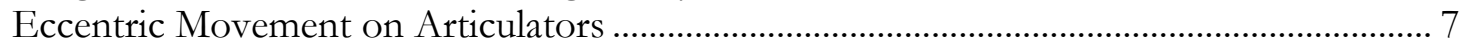

CHAPTER 3: MATERIALS AND METHODS ..................................................... 8

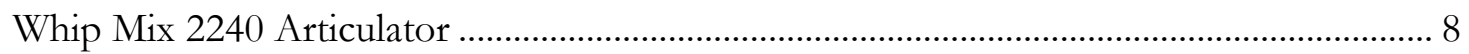

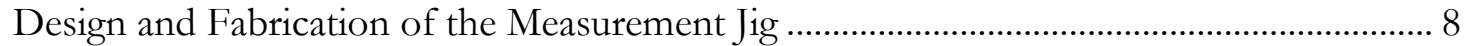

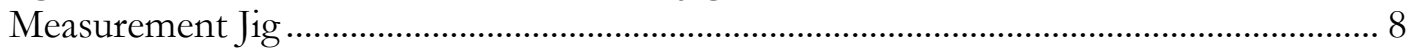

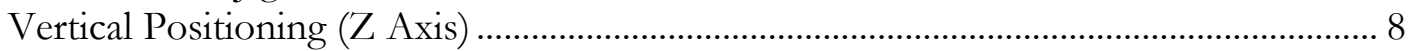

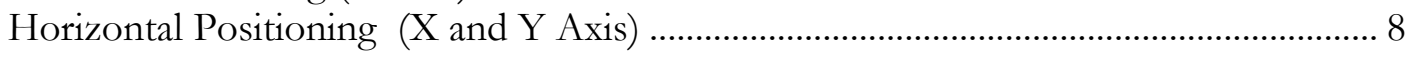

Setting the Angle between the Upper and Lower Members of the Articulator ............. 13

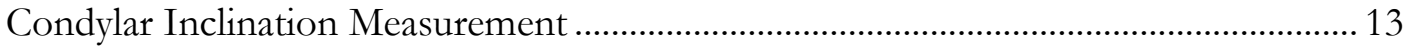

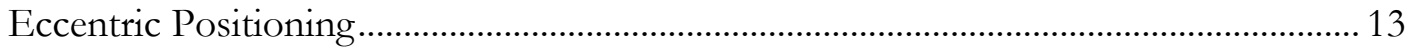

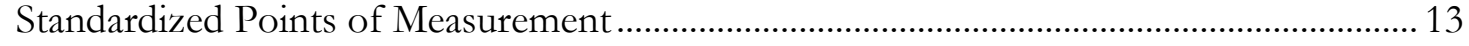

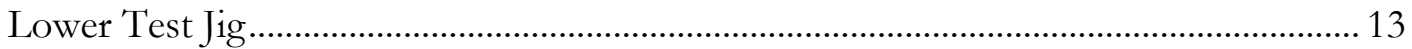

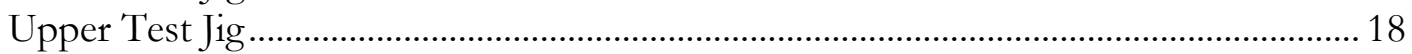

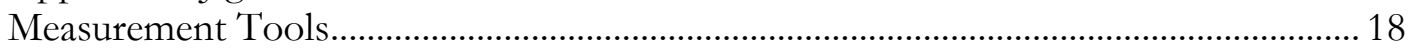

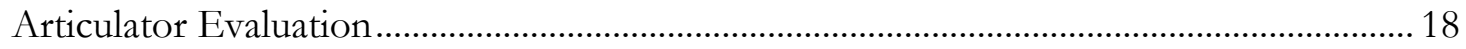

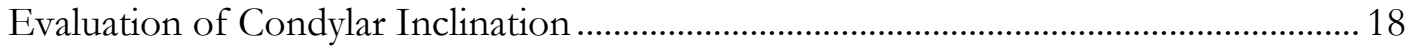

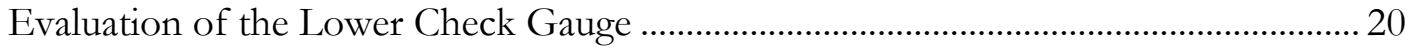

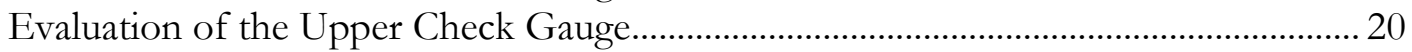

Evaluation of the Eccentric Movement............................................................................ 20

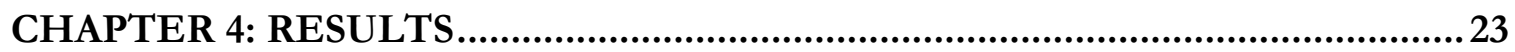

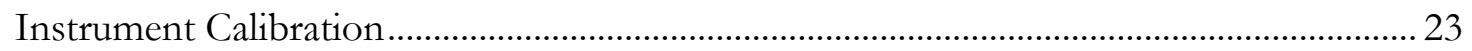

Evaluation of Visually Programmed Condylar Inclination ................................................. 23

Reproducibility of 3D Positioning of the Lower Member within the

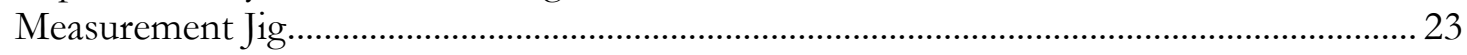

Reproducibility of 3D Positioning of the Upper Member within the

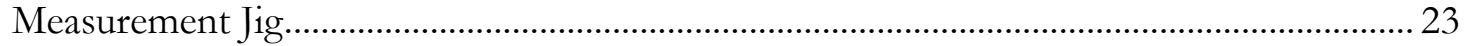

Reproducibility of 3D Positioning of the Upper Member within the

Measurement Jig during a Prescribed Eccentric Movement................................................. 25

Net Change in Spatial Position from Hinge Closure of the Upper Member during a

Prescribed Eccentric Movement ............................................................................................. 25 


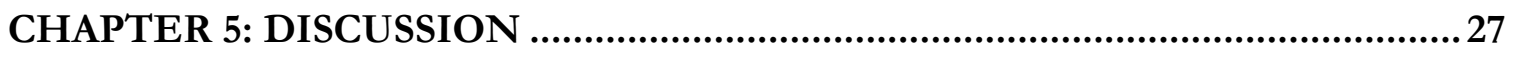

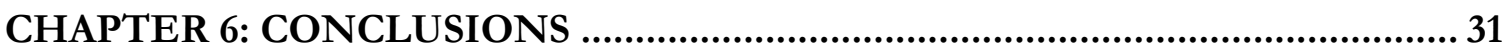

CHAPTER 7: LIMITATIONS AND FUTURE DIRECTIONS.............................32

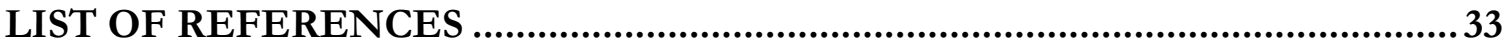

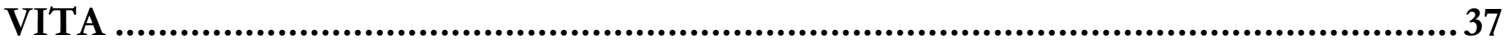




\section{LIST OF TABLES}

Table 4-1. Condylar Inclination Set by Operator Eye ............................................................. 24

Table 4-2. Positioning of the Lower Articulator Member within the Measurement Jig .... 24

Table 4-3. Positioning of the Upper Articulator Member within the Measurement Jig in Hinge Closure ................................................................................................ 24

Table 4-4. Eccentric Positioning of the Upper Articulator Member within the Measurement Jig 26

Table 4-5. Average Spatial Change in Prescribed Eccentric Movement ............................... 26

Table 5-1. Interchangeability Studies and Quantified Error in Hinge Closure ................... 28 


\section{LIST OF FIGURES}

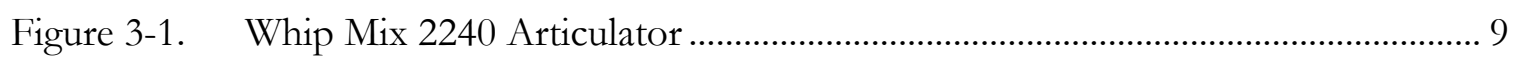

Figure 3-2. Whip Mix 2240 Intercondylar Width ........................................................... 9

Figure 3-3. 3/4" Curvilinear Condylar Housings.................................................................. 10

Figure 3-4. Fixed 7.5 Degree Progressive Side Shift, Adjustable Immediate Side Shift .... 10

Figure 3-5. Experimental Measurement Jig ........................................................................ 11

Figure 3-6. Dowel Pins and Toggle Lock as a Means of Standardizing Lower Member Position

Figure 3-7. Measurement Jig Top Plate ……......................................................................... 12

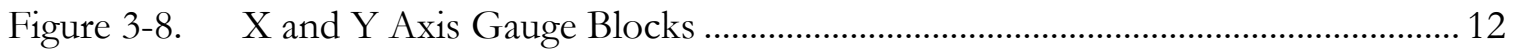

Figure 3-9. Setting the Angle between the Upper and Lower Members............................... 14

Figure 3-10. Measurement of Condylar Housing Inclination .................................................. 14

Figure 3-11. Average Value Positioning of Test Gauges ......................................................... 15

Figure 3-12. The Eccentric Arm, Eccentric Pin and Z Block................................................ 16

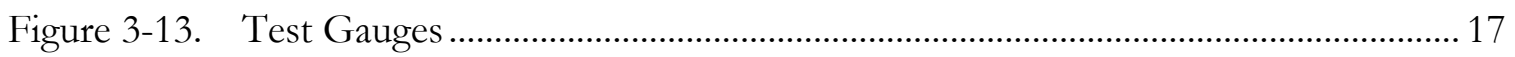

Figure 3-14. Measurement Tools .............................................................................................. 19

Figure 3-15. Lower Test Gauge $\mathrm{X}$ and $\mathrm{Y}$ and $\mathrm{Z}$ Axis Measurements .................................... 21

Figure 3-16. Upper Test Gauge $\mathrm{X}$ and $\mathrm{Y}$ and $\mathrm{Z}$ Axis Measurements.................................... 21

Figure 3-17. Upper Test Gauge Eccentric Measurements ..................................................... 22 


\title{
CHAPTER 1: INTRODUCTION AND BACKGROUND
}

\author{
The Purpose of Dental Articulation
}

The purpose of dental articulation is to produce an approximation of the patient's mandibular motion in order to study its condition and aid in diagnosis and therapy. Precise mechanical reproduction of the intraoral condition is the desired end goal of articulation for it allows for the most accurate diagnosis and fabrication of dental devices (Stuart 1959).

If a dentist can transfer the patient's dental axis relations and movement capability to the laboratory bench, restorations with greater accuracy may be produced. Ultimately, patient treatment time may be reduced while improving the overall accuracy of the dental prosthesis.

\section{Instrumentation}

The first instruments for dental articulation were very simple hinges. These instruments held casts and permitted dynamic approximation, i.e. opening and closing, of the casts, typically incorporating an anatomically unrealistic axis of movement. In general, these simple instruments do not have the ability to accurately replicate jaw movements.

As dentistry developed in the early twentieth century, innovative engineering processes developed mechanisms to record three-dimensional mandibular movement. For the first time, precise instrumentation was available to record and facilitate the reproduction of human jaw movement. Articulator systems capable of such accuracy are commonly referred to as fully-adjustable instruments (Hobo et al. 1976). In order to accurately program a fully-adjustable instrument to reproduce a single patient's mandibular movement, sophisticated recording devices called pantographs are often used (Kornfeld 1974).

Fully-adjustable articulators are generally accepted as the most accurate instruments of articulation, yet they are seldom employed in routine dental therapy. These instruments are more expensive, time consuming, and technique sensitive when compared to more common modes of articulation. The demand for skill, attention to detail, in addition to increased clinical time and cost, render this form of instrumentation impractical for routine localized treatment plans in the average dental office (Hobo et al. 1976).

Semi-adjustable articulators may be viewed as a compromise between simple hinge instruments and fully-adjustable articulators. Average values have been built into these less adjustable articulators. While average values into elements of the articulator may simplify and expedite use, each approximation introduces the possibility of inaccurate three-dimensional dynamic relationships in dental articulation (Wachtel and Curtis 1987).

Common average values or approximations utilized in the semi-adjustable articulator are: arbitrary hinge axis, incorporation of an arbitrary hinge axis location and transfer, average intercondylar distance, fixed medial wall and immediate side shift, and linear progressive side-shift (Shillingburg et al. 1997). Manufacturers have developed diverse combinations of these factors to satisfy the intended goals. Each average value element built 
into an articulator may lead to error in restorations. In turn this may lead to adjustment must consume clinical chair time for occlusal correction. If appropriate occlusal correction is not accomplished, the inaccurate restorations can be a source of potential occlusal pathology (Hobo et al. 1976).

Occlusal contact errors in centric or hinge closure are often referred to as prematurities. Non-desired contacts during eccentric mandibular movements are called interferences. Malocclusion, defined by the 2005 Glossary of Prosthodontic Terms, is any deviation from a physiologically acceptable contact between opposing dental arches. Malocclusion has been implicated as a cause of dental pain, periodontal disease, tooth mobility and fracture, myofascial pain, temporo-mandibular disorders and tinnitus. The impact of occlusion on these topics is argued in literature (Costen 1934; Pilhstrom et al. 1986; Clark 1999).

\section{Recommended Instrumentation from American Dental Schools}

The most commonly used and recommended articulator in American dental schools classify as semi-adjustable (Taylor et al. 1985; Petropolous et al. 1998; Clark et al. 2001). An ear-bow is most often used to locate dental casts within the semi-adjustable articulator in order to closely approximate the mandible's axis of rotation. Most semi-adjustable articulators do not allow for individualized adjustment of inter-condylar width and do not have the ability to simultaneously adjust for immediate and progressive side-shift. The magnitude of occlusal error from the use of a semi-adjustable articulator likely relates to how close the patient characteristics coincidentally match the average value elements built into the articulator chosen (Hobo et al. 1976).

\section{Limitations of Semi-Adjustable Articulators}

When employed with a face-bow, semi-adjustable articulators reproduce a patient's hinge axis closure of mandible. Semi-adjustable articulators using face-bows can be relied upon to approximate mandibular motion hinge axis closure only. The face-bow is designed to closely approximate the relationship between the mandibular hinge axis and the maxillary dental arch using interocclusal records. If the patient's arbitrary hinge axis is not co-incident with the true hinge axis, significant occlusal discrepancies may result (Bergstrom 1950; Schallhorn 1957; Beck 1959; Lauritzen and Bodnar 1961; Teteruck and Lundeen 1966; Simpson et al. 1984; Palik et al. 1985).

Studies on arbitrary/average value axis approximations achieve near consensus that a 5-6mm axis location error is common (Teteruck 1966; Palik 1985). Weinberg studied the occlusal discrepancies produced with hinge axis error of $5 \mathrm{~mm}$. The $5 \mathrm{~mm}$ error in hinge axis produced a $0.2 \mathrm{~mm}$ anterior posterior occlusal discrepancy when measured at the second molar (Weinberg 1959; Weinberg 1963). The level of occlusal discrepancy reported by Weinberg is commonly cited as acceptable for a general practitioner (Wilkie 1979; Zuckerman 1982; Simpson et al. 1984). Wachtel and Curtis (Curtis and Wachtel 1987; Wachtel and Curtis 1987) described the limitations of semi-adjustable articulators reporting positive errors are most likely in the horizontal plane. Positive error can be largely removed 
by increasing average settings, but predictably results in blunted and shallow occlusal morphology.

\section{What Is Interchangeability?}

Articulator interchangeability is the ability to transfer dental casts from one articulator to another articulator without loss of clinical accuracy. This is commonly employed where the dentist and the technician have the same model instrument and only casts need be transported between the office and the lab.

\section{Manufacturer's Claims}

Many articulator systems purport interchangeability as a means of decreasing equipment cost without sacrificing clinical outcome (Artex 2010; Panadent 2010; Whip Mix 2010). These systems concurrently offer additional advantages in infection control, decreased shipping costs and related damage (Price and Mansfeild 1999; Price et al. 2001). These features are desirable characteristics for an instrument being considered for use by a dentist and laboratory. To calibrate their instruments in the factory and subsequently in the lab or office, manufacturers have fabricated calibration tools and other devices. Some, but not all, of these claims and devices have been studied in scientific literature (Cowan et al. 1991; Kitzis et al. 1991; Unger et al. 1991; Sanchez et al. 1993; Price and Mansfeild, 1999; Price et al. 2000; Chung et al. 2001; Dexter et al. 2001; Hatzi et al. 2001; Price et al. 2001). The efficiency afforded by interchangeability has the potential to increase the frequency of use of these articulators compared with simple hinge instruments, thus increasing the comparative quality of dental care.

\section{The Problem of Eccentricity}

Semi-adjustable interchangeability in hinge closure addresses only part of the problem. Occlusal interferences in articulated dental casts can result if the articulators do not accurately replicate each other's eccentric movements. The potential for occlusal error in eccentric articulator positions is greater than during simple hinge closure. While hinge closure interchangeability is primarily related to the hinge tolerances of the articulator, eccentric interchangeability relies upon the machining tolerances of the condylar elements and the ability of the operator to program the condylar controls of the articulator accurately.

Studies to address these uncertainties do not appear in a search of published dental literature. Therefore, the purpose of this project was to investigate the capacity of a semiadjustable articulator that claims interchangeability, to reproduce controlled eccentric movement. The hypotheses tested were:

- A single operator can precisely and accurately adjust the horizontal condylar inclination on a series of articulators to within one degree of a prescribed setting when measured by a digital angle gauge. 
- A novel measurement jig permits measurement of articulator interchangeability that is repeatable within the range reported in similar studies.

- A prescribed lateral movement on a series of new articulators positions a specific measurement point (maxillary first bicuspid facial cusp tip) in the same spatial location within tolerance reported for hinge axis closure of calibrated instruments.

- A prescribed lateral movement on a series of used articulators positions a specific measurement point (maxillary first bicuspid facial cusp tip) in the same spatial location within tolerance reported for hinge axis closure of calibrated instruments. 


\section{CHAPTER 2: REVIEW OF LITERATURE}

\section{Hinge Axis Closure and Interchangeability}

Semi-adjustable articulators claiming interchangeability include Whip Mix 2240 and 3040, Dentate ARL, Denar, Panadent PCH, Ivoclar Stratus, Hanau Modular and Wide Vue and the Girrbach Artex. Not all of these claims of interchangeability have been supported by published literature, even tough several authors have studied the interchangeability of semiadjustable articulators (Cowan et al. 1991; Kitzis et al. 1991; Unger et al. 1991; Sanchez et al. 1993; Price and Mansfeild 1999; Chung et al. 2001; Dexter et al. 2001; Hatzi et al. 2001; Price et al. 2001).

Unger et al. (1991) described Dentatus ARL instrument calibration using a U-joint attached to the articulator's hinge axis and a gauge. Examination of articulator calibration was performed using shimstock at specified points between mounted casts. The authors quantified gauge contact from 0-3. No resistance to shimstock removal was scored zero, some resistance was scored 1, and total resistance was scored 3. Results indicated that casts were not interchangeable following calibration and variation existed between different gauge blocks. Ironically, the tools used to calibrate the accuracy and interchangeability of the instrument were ultimately inaccurate. The manufacturer recommends that the interchangeability of this instrument is reliable only for denture tooth setup. Final denture adjustments must be made on the articulator that originally received the primary cast mountings.

Kitzis et al. (1991) evaluated the Denar system of interchangeability via the Denar Field Inspection Gauge. The Field Inspection Gauge involves two monocular microscopes attached to the upper member of the articulator and a stage with reticule and crosshairs on the lower member. In addition, vertical relations and medio-lateral cant is adjusted with dial height gauges. This far more elaborate system was tested on 12 instruments via the split cast experimental design. Complete calibration was achieved though this method, but no attempt was made to quantify the calibration status in terms of tolerance.

The Whip Mix 2240 claim of articulator interchangeability was evaluated against the non-interchangeable Whip Mix 8500 by Cowan (1991). In an attempt to quantify spatial calibration a novel device was fabricated with 3 styli attached to a mounting plate. The styli were then adjusted to contact a remount plate attached to the lower member with pressure sufficient to hold shimstock. Marking the points of contact with graph paper affixed the lower member remount plate allowed for comparison between instruments in the mediolateral plane. Shimstock was used to assess the vertical calibration via: 1) no resistance to shimstock removal, 2) tug resistance to removal and 3) tear shimstock on removal. In a survey of 8 articulators the evaluator found that all held $13 \mu \mathrm{m}$ shimstock and horizontal misfit ranged from $0.00-0.08 \mathrm{~mm}$ when measured under magnification.

Sanchez et al. (1993) evaluated the Hanau modular articulator using a similar protocol to that used by co-author Cowan in 1991. This study added a 4+ qualitative scale intended to shed more light on vertical calibration. Calibration was ascribed to styli with a 
light tug of shimstock on withdrawl. At minimum light tug was observed in 22 out of 24 styli. Vertical misfit was assessed at less than $0.038 \mathrm{~mm}$. The horizontal calibration was measured under a microscope and ranged from $0.00-0.29 \mathrm{~mm}$, which is less than the manufacturer's claim of $0.33 \mathrm{~mm}$. A concern described in this study and impacting the previously reported study is that the tip diameter of the styli was approximately $0.25 \mathrm{~mm}$ (Cowan et al. 1991).

Following a period of 1-6 years of service Price and Mansfield assessed the calibration status of 46 used Whip Mix articulators using the Whip Mix 2245 check gauge (Price and Mansfield 1999). Further evaluation of the mismatch between gauge surfaces and an attempt to quantify the degree of misfit was performed with leaves of $26 \mu \mathrm{m}$ shimstock. $83 \%$ passed this test for interchangeability however, most articulators bore less than $26 \mu \mathrm{m}$ vertical discrepancy but of the 3 of the sample measured greater than $52 \mu \mathrm{m}$ of space. The authors conclude that these articulators are of sufficient interchangeable precision for routine clinical procedures over the observed time period and recommended routine checks of calibration.

The Whip Mix claim of interchangeability was re-evaluated by Price with similar protocol but a sample of 38 model 2240s and 71 model 3040 articulators (Price et al. 2001). 93\% of instruments tested were as claimed interchangeable with 4 failures from each model. The vertical misfit was assessed at 4 locations per instrument and greater than $99 \%$ of measurements were less than $52 \mu \mathrm{m}$. Trends to the left anterior in misfit location caused the authors to suspect screw type mounting plate torque as a possible cause of misfit. They also postulate the model 3040 and 2240 may be excursively interchangeable, but this topic requires further study. The reason for the failure of the new instruments was not explained except that the manufacturer may have used a slightly different instrument and/or method (Price et al. 2001).

Chung et al. (2001) tested the Hanau Wide Vue instrument with the Denar field inspection gauge. Equal groups of 10 instruments categorized as new, 18 months of age, and 30 months of age, were evaluated against manufacturer's claim of $102 \mu \mathrm{m}$ horizontal tolerance. The investigators referenced cast mounting accuracy as the rationale for vertical tolerance of $166 \mu \mathrm{m}$ (Piesingher and Breeding 1995). Their rationale was instruments need not a tolerance greater than cast mounting tolerance. The authors concluded that within a tolerance of $102 \mu \mathrm{m}$ horizontally as claimed by the manufacturer 9 of 10 new instruments were interchangeable. Most instruments deviated less than $250 \mu \mathrm{m}$ and this level of calibration was maintained for 18 months.

Hatzi et al. (2001) assessed the Kavo Protar, Girrbach Artex AL and Whip Mix 3040 articulator systems via an occlusal registration method to assess hinge axis repeatability. Light transmission through multiple vinyl polysiloxane hinge closure records was used to compare contacts within 5 instruments from each group. Their conclusions were that the tested systems were in fact not interchangeable. However, the Artex and Kavo systems were more consistent in the production of occlusal contacts. The light transmission method used to assess contacts is well described, but of limited capacity to produce quantified error. 


\section{Eccentric Movement on Articulators}

Chou and Pameijer (1987) compared the TMJ, Denar D4A Panadent PC and the Hanau $\mathrm{H} 2$ using the Visi-trainer tracing device. Their results indicated that differences existed between the patient and the all instrument-generated pathways. The greatest discrepancies between the patient and the instrument occurred in the horizontal plane having impact on posterior occlusal morphology.

Tamaki et al. (1997) utilized high-tech axiographic data to mount cases on a SAM semi-adjustable articulator in an attempt to reproduce eccentric contacts. This experiment was unable to reproduce cuspid rise single tooth contacts, $10 \%$ of the time. Conclusions drawn for reproduction of greater than one simultaneous contact were suspect due to the inherent flexibility of the oral supporting structures, the inflexibility of casts, dimensional variability of casts and type of cast-mounting procedures utilized, in addition to the limited adjustability of the articulation system chosen. 


\title{
CHAPTER 3: MATERIALS AND METHODS
}

\author{
Whip Mix 2240 Articulator
}

The subject of this study is the Whip Mix 2240. The 2240 is an open track, arcon articulator with fixed inter-condylar width set $110 \mathrm{~mm}$. Condylar elements contain a $3 / 4$ " curvilinear track with fixed 7.5 degree progressive side-shift and provision for adjustment of immediate side-shift (Whip Mix 2011). The articulator is claimed interchangeable with magnetic mounting plates or screw type mounting plates. Figures 3-1, 3-2, 3-3 and 3-4 illustrate several of the design features of the Whip Mix Model 2240 articulator.

\section{Design and Fabrication of the Measurement Jig}

\section{Measurement Jig}

Heavy gauge precision stock aluminum was used to construct a measurement jig to evaluate articulator position in 3 axes. Figure 3-5 displays the different elements of the measurement jig. The jig platform was used as zero position for the $\mathrm{Z}$ axis measurements and assessment of condylar angle.

\section{Vertical Positioning (Z Axis)}

The Whip Mix 2245 articulator comes manufactured with rubber bushings as cushion on hard surfaces and for grip on smooth surfaces. Dowel pins were added to the measurement jig in order to standardize the vertical positioning of the articulators. Figures 3-5 and 3-6 depict the position and experimental utility of the dowel pins in positioning the articulator. A toggle lock was added to secure the lower member in position for the duration of testing. Figures 3-5 and 3-6 also illustrate the features of the measurement jig that control the vertical positioning.

\section{Horizontal Positioning ( $\mathrm{X}$ and Y Axis)}

In Figure 3-7 the Whip Mix 2245 articulator was positioned with its right condyle post in a machined right angle notch in the top plate of the measurement jig. Figure 3-7 shows how the left condyle was then braced against the top plate thereby standardizing the $\mathrm{X}$ and $\mathrm{Y}$ axis. Predictable horizontal positioning in measurement jig afforded consistency to the measurement in this plane. Gauge blocks, as pictured in Figure 3-8, were attached to the measurement jig and provided a stable, consistent start point for measurements in the $\mathrm{X}$ and Y axes. 

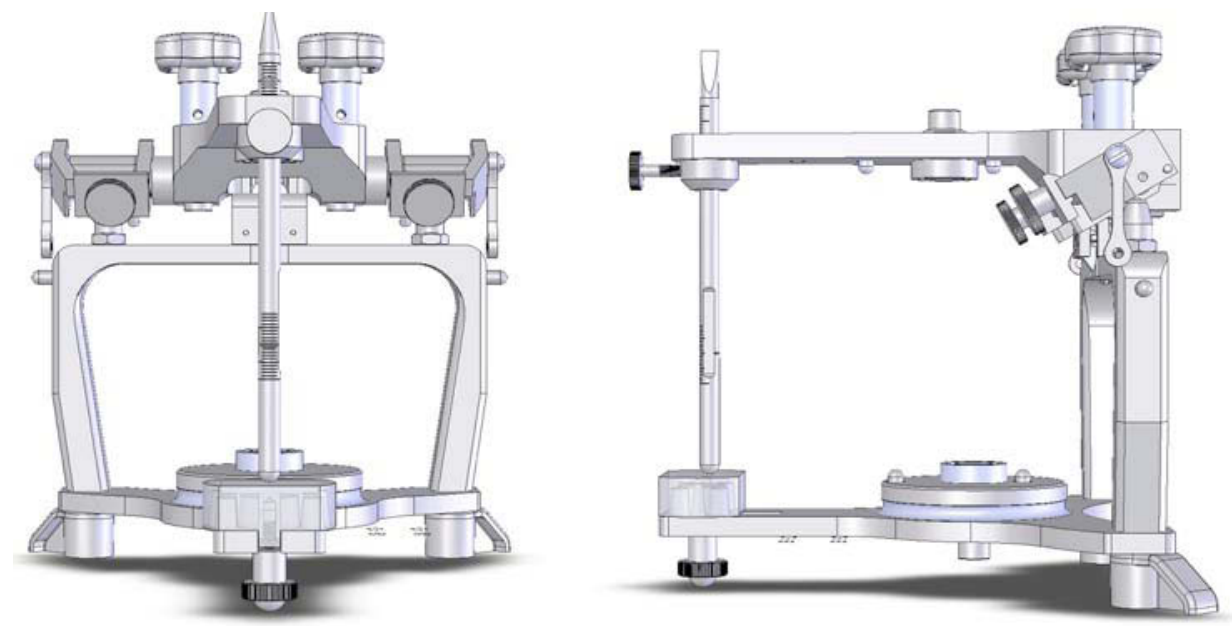

Figure 3-1. Whip Mix 2240 Articulator.

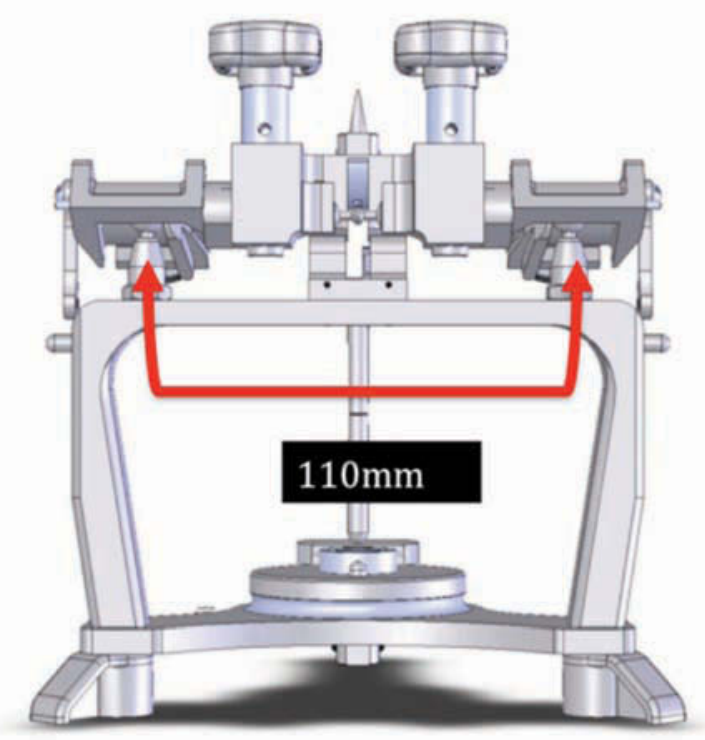

Figure 3-2. Whip Mix 2240 Intercondylar Width. 

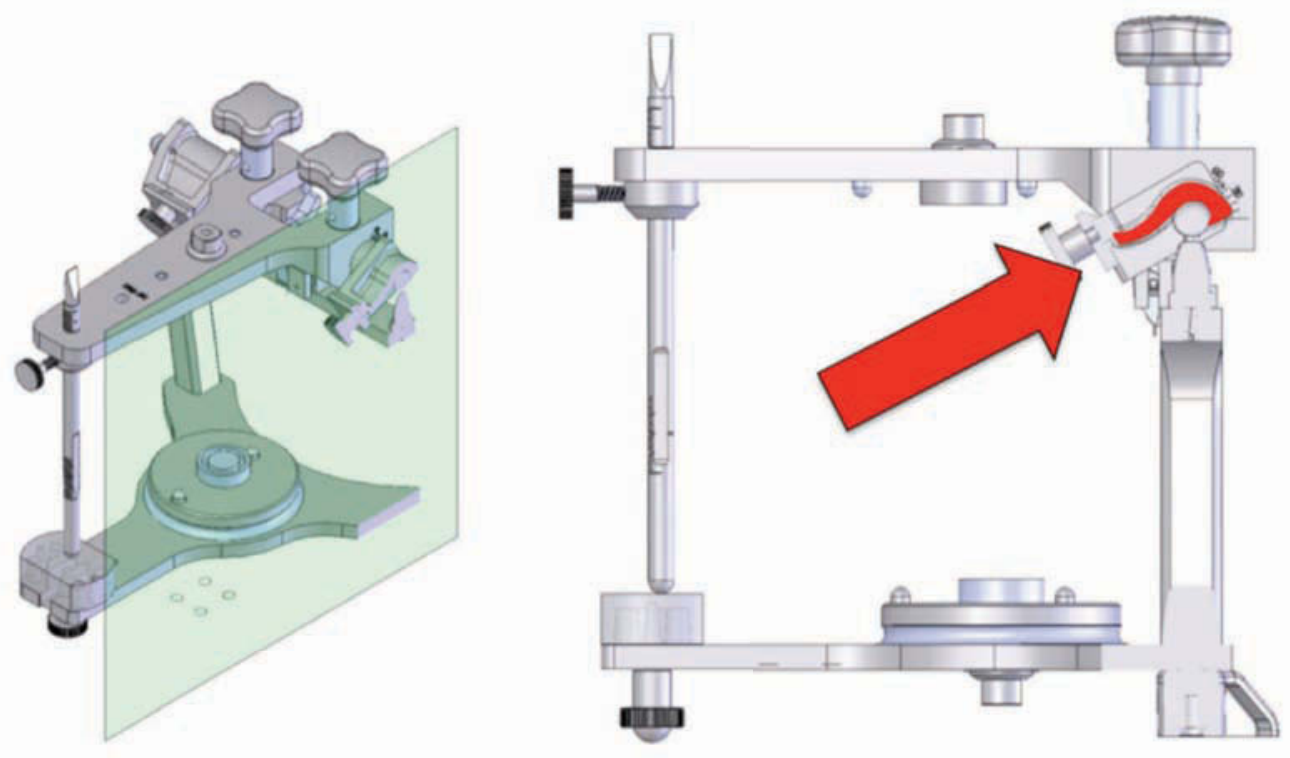

Figure 3-3. 3/4" Curvilinear Condylar Housings.

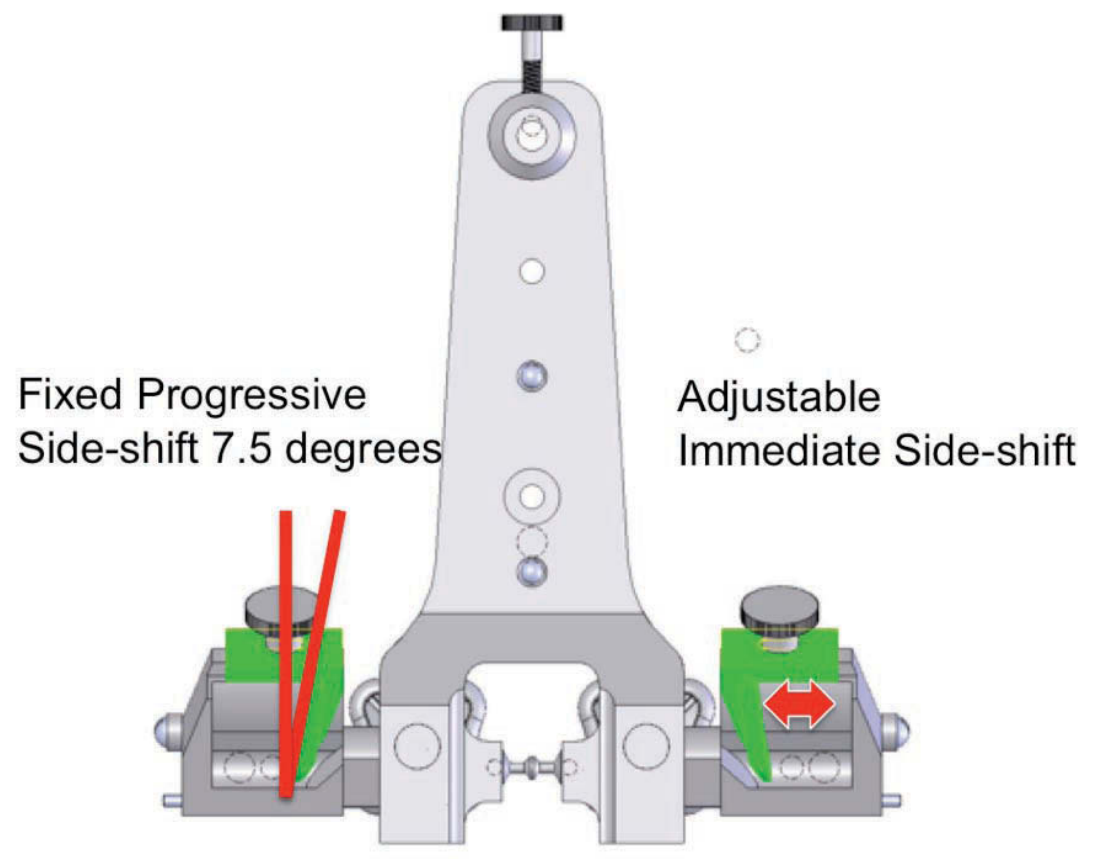

Figure 3-4. Fixed 7.5 Degree Progressive Side Shift, Adjustable Immediate Side Shift. 


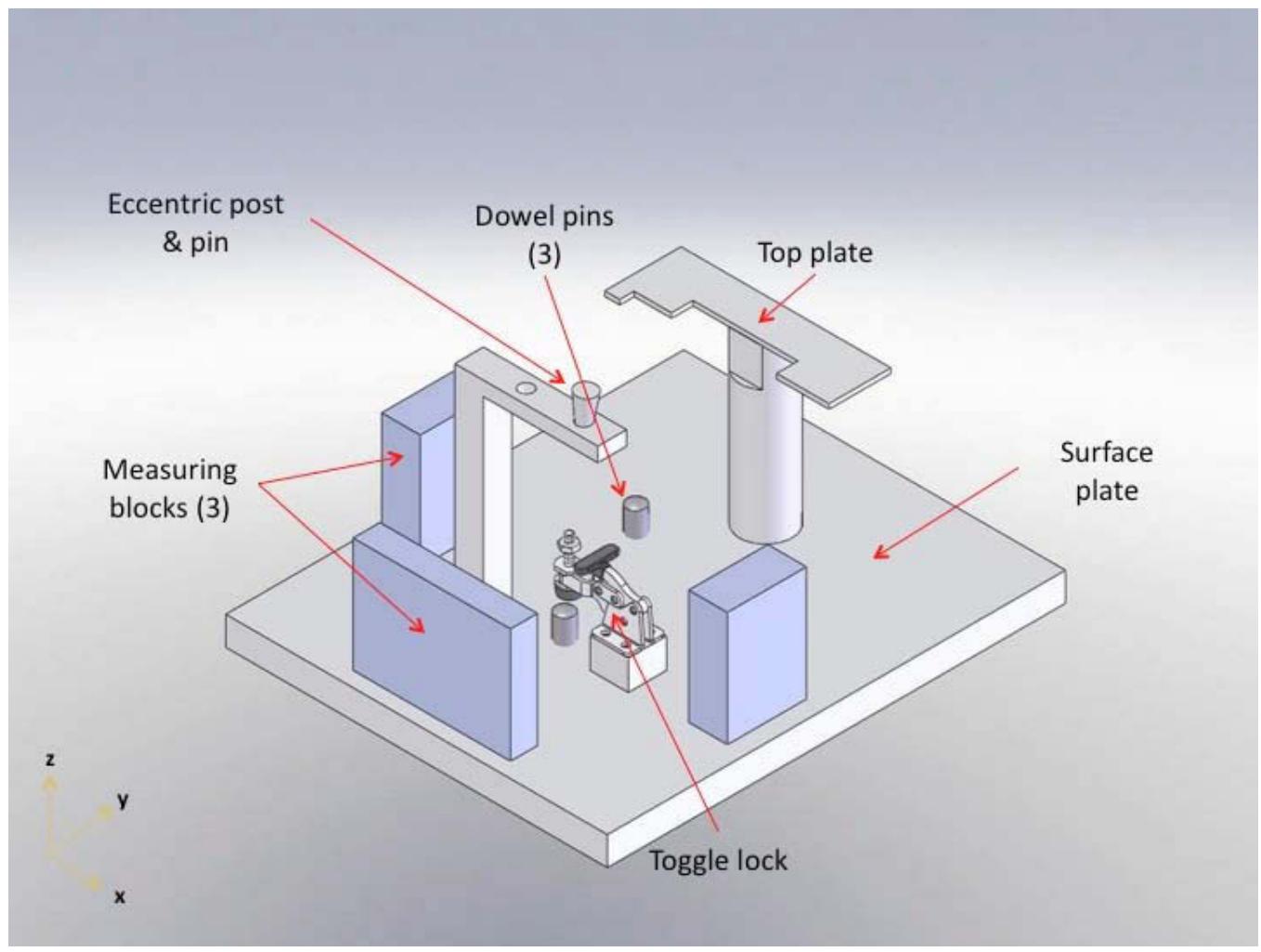

Figure 3-5. Experimental Measurement Jig.
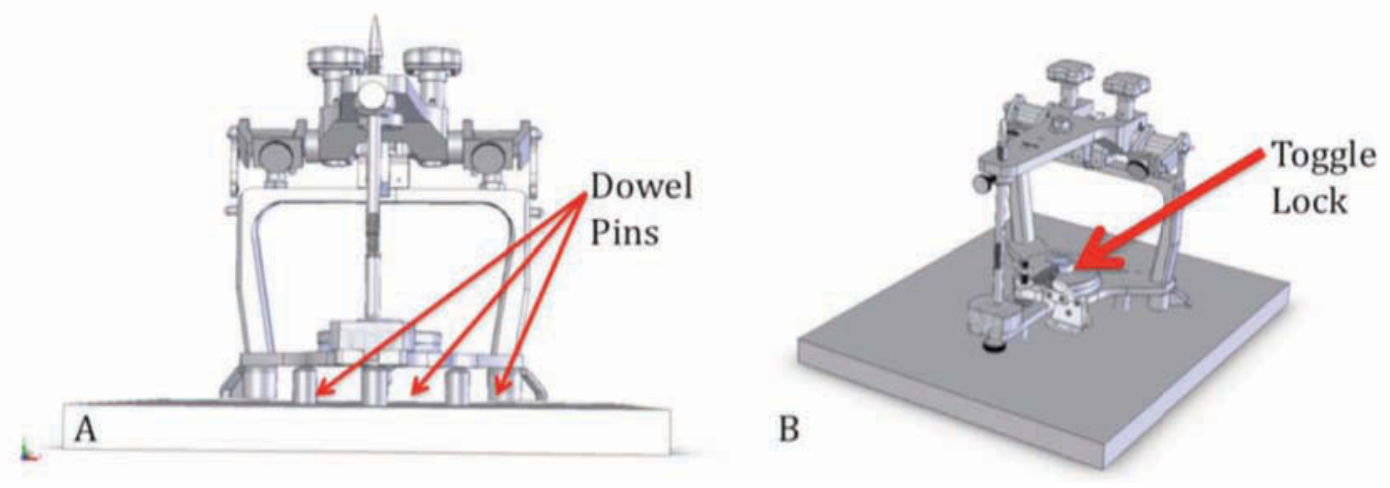

Figure 3-6. Dowel Pins and Toggle Lock as a Means of Standardizing Lower Member Position.

A. Location of the dowel pins on the measurement jig. B. The toggle lock secures the lower member on top of the dowel pins. 


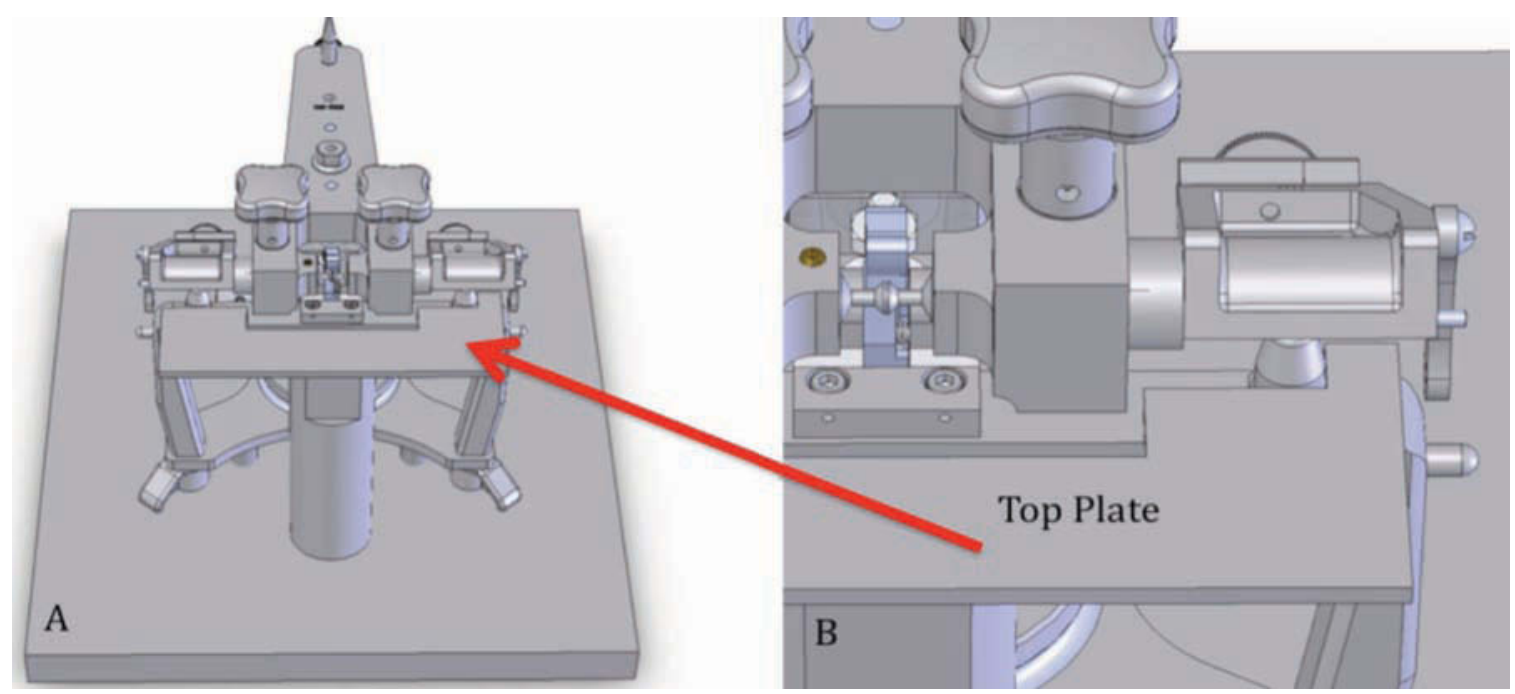

Figure 3-7. Measurement Jig Top Plate.

A. Top plate positioning in the measurement jig. B. The relationship of the condyle post to the top plate.
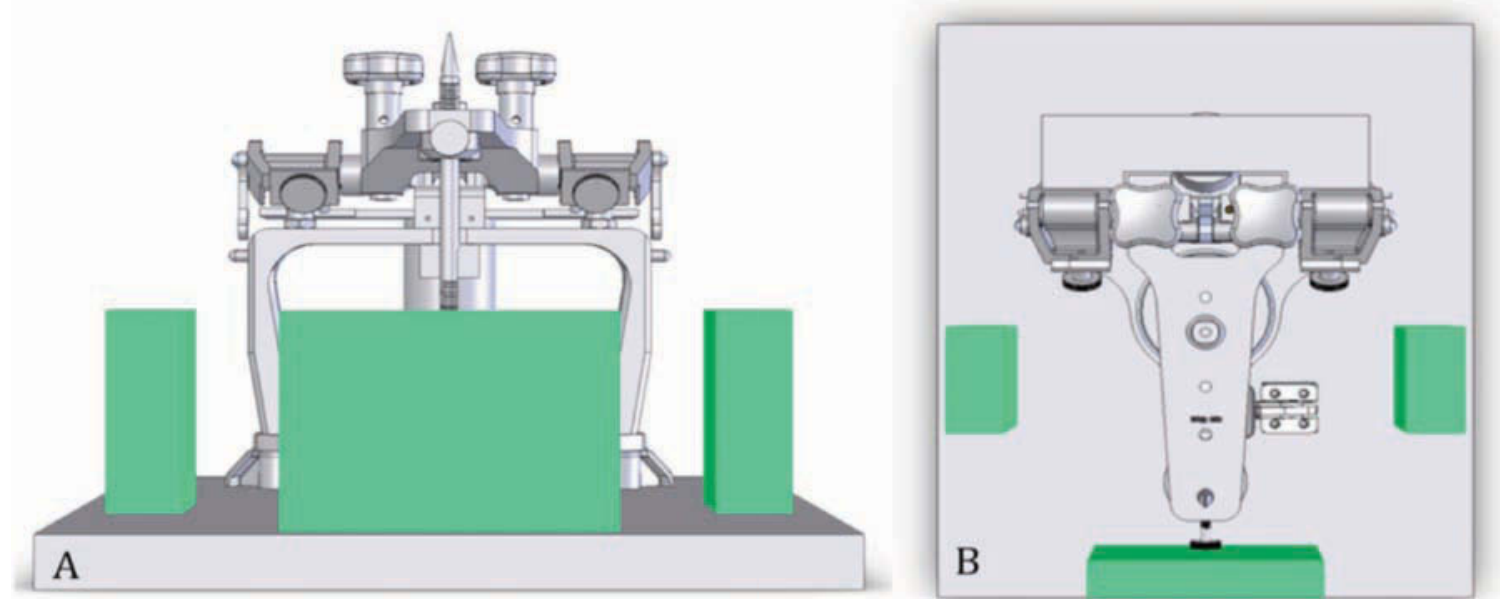

Figure 3-8. $\mathrm{X}$ and $\mathrm{Y}$ Axis Gauge Blocks.

A. Overview of the gauge block positioning relative to the articulator. B. Vertical relationship between the gauge blocks and the test gauges. 


\section{Setting the Angle between the Upper and Lower Members of the Articulator}

Employing the 2245 check gauge, the same tool used to verify calibration, articulators were standardized for the amount of rotation about their hinge axis. This afforded consistency in the measurement of the condylar inclination and served as a starting point for the eccentric measurement. Figure 3-9 demonstrates the spatial positioning of the upper and lower member by means of the 2245 check gauge.

\section{Condylar Inclination Measurement}

A small piece of flat aluminum precision stock was cut to fit along the top surface of the Model 2245 condylar housing. The manufacturer confirmed the general relationship of the upper surface of the condylar housing to the condylar inclination (Mike Lade, Whip Mix Corp., personal communication, November 2010). Upon this flat plane, a digital angle gauge was employed to assess the difference in angulation between the housing and the base of the measurement jig. Figure 3-10 depicts the relationship between the angle gauge and the condyle housings.

\section{Eccentric Positioning}

Unique test gauges were fabricated (Whip Mix Corp., Louisville, KY). These gauges bore targets that represented the buccal cusp tips of maxillary and mandibular buccal cusp tips of a cast set by average. The average values used to position the targets bisected the upper and lower members and positioned the central incisors $100 \mathrm{~mm}$ from each condyle, approximating Bonwill's 4 inch triangle theory (Bonwill 1899). Figure 3-11 illustrates the positioning of the upper and lower test gauges relative to Bonwill's triangle.

Eccentric movement from centric position involves both a vertical and a horizontal component, the test gauges incorporated a $Z$ block that produced a controlled vertical displacement. Horizontal eccentric movement was limited by contact of the upper and lower gauges and maintained by the use of a conical friction fit Eccentric Pin. The net result was a measured and reproducible movement in 2 planes when measured in the measurement jig. Figure 3-12 illustrates the Eccentric arm, Eccentric Pin and Z Block.

\section{Standardized Points of Measurement}

\section{Lower Test Jig}

The target of measurement was the intersection of the 3 planes on the lower test gauge. Figure 3-13A displays the lower test gauge with the target of the all measurements being the intersection of the 3 planes as marked. 

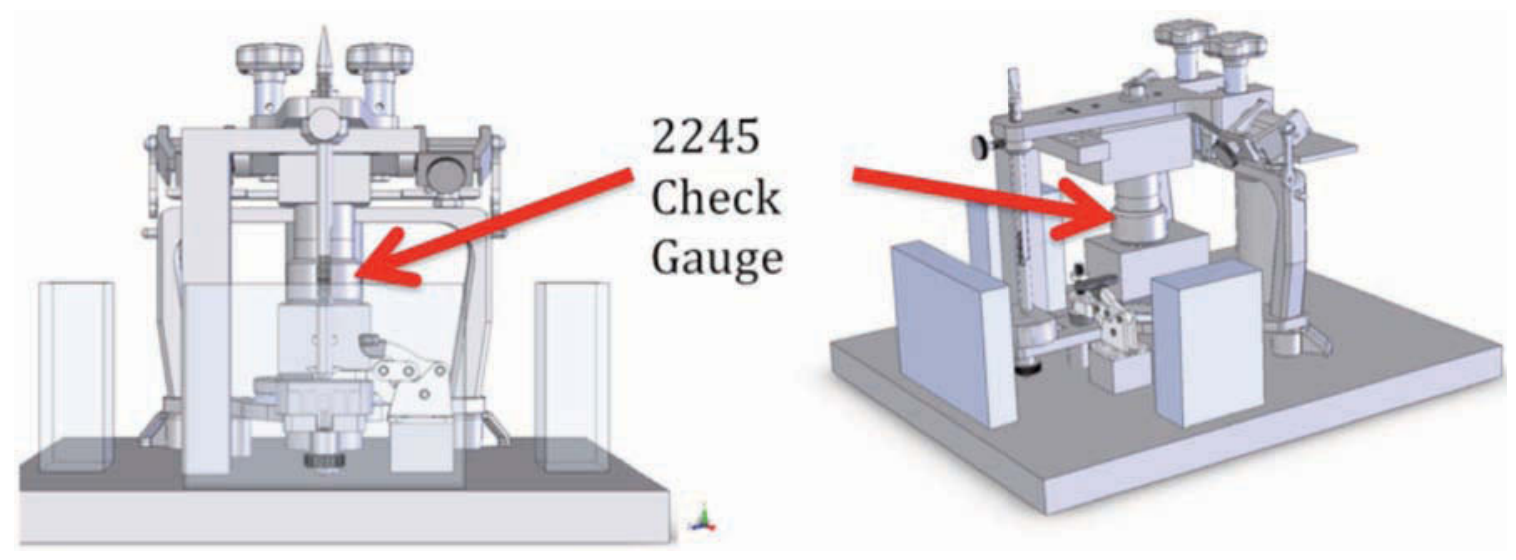

Figure 3-9. Setting the Angle between the Upper and Lower Members. A. 2245 check gauge frontal. B. 2245 check gauge in offset lateral view.

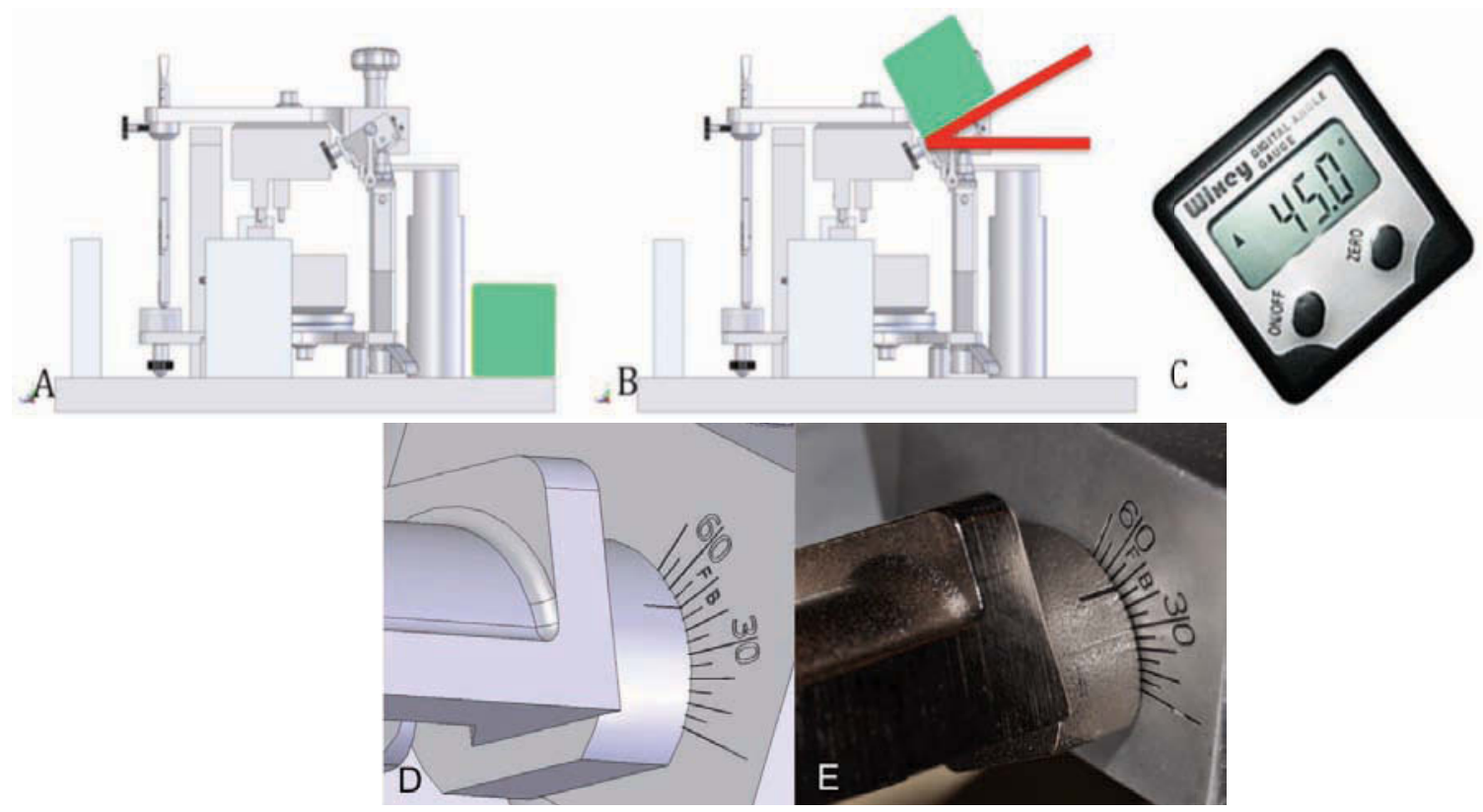

Figure 3-10. Measurement of Condylar Housing Inclination.

A. Digital angle gauge in the zero position on the measurement jig base. B. Depicts the orientation of the angle gauge to the measurement jig when in place atop the programmed condyle at setting "FB." C. 2" digital angle gauge (Barry Wixley Development, Seattle, WA) reported accuracy of 0.01 ". D. Condyle programmed to FB in CAD drawing. E. Condyle programmed to FB photograph from experiment. 


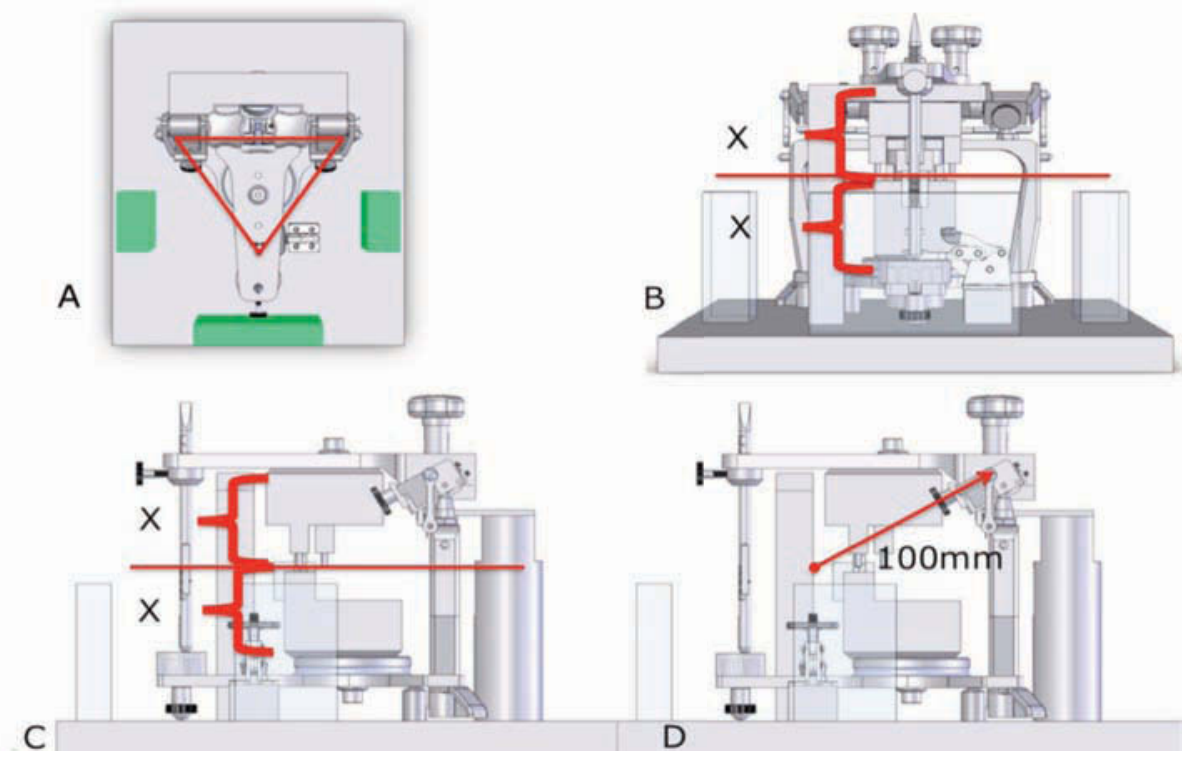

Figure 3-11. Average Value Positioning of Test Gauges.

A. Bonwill's equilateral triangle overlaid on the articulator and measurement jig. B and C. The upper and lower test gauges positioned within the articulator. D. The distance from the incisor point to the condyle is $100 \mathrm{~mm}$. 


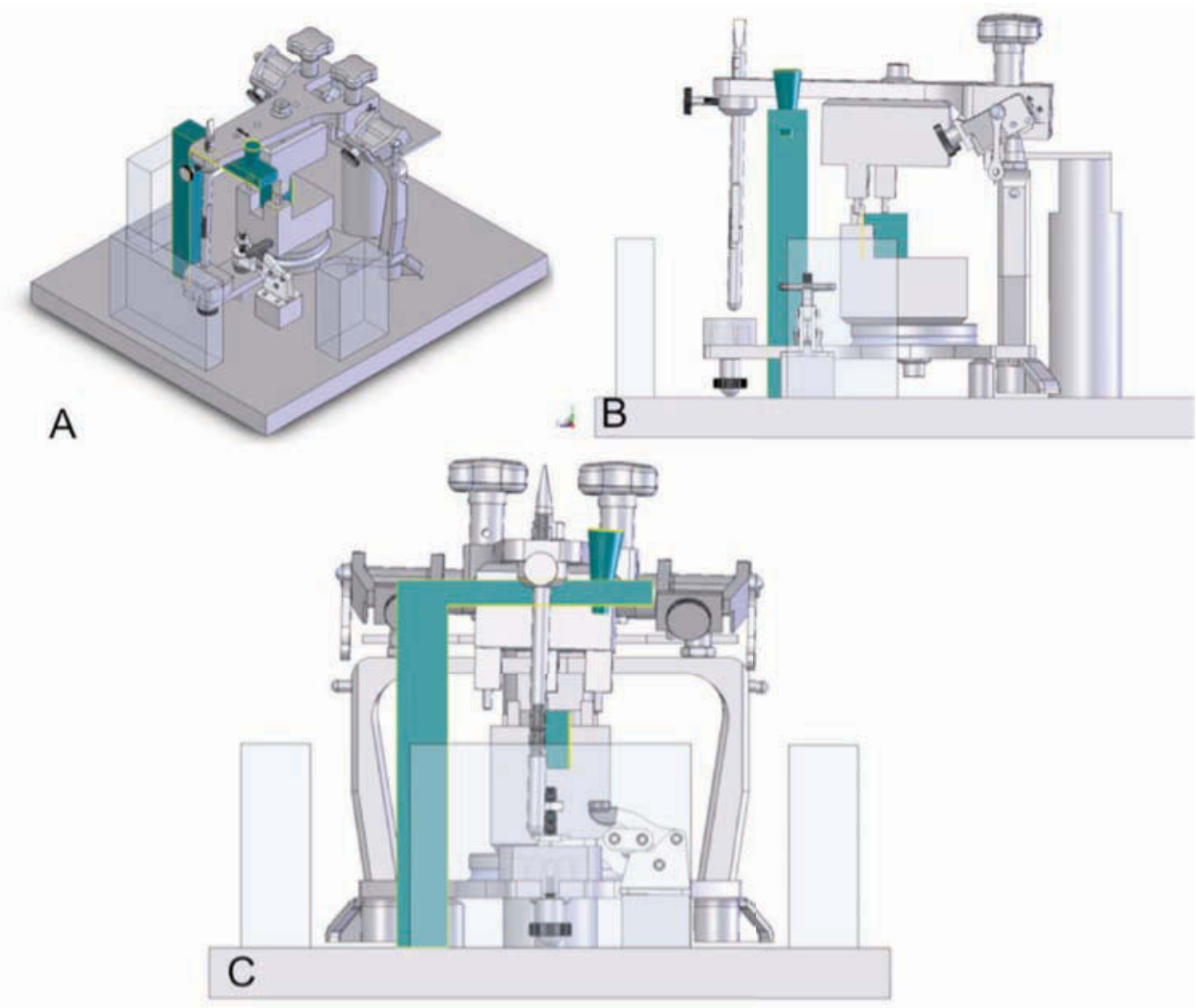

Figure 3-12. The Eccentric Arm, Eccentric Pin and Z Block.

A. Overview. B. Right lateral view of the Z Block. Note: the vertical change in pin position. C. Frontal view of the Eccentric Arm Eccentric Block and Eccentric Pin. Note: the change in $\mathrm{X}$-axis movement is limited by the Upper Check Gauge contact and stabilized by the Eccentric Pin. 


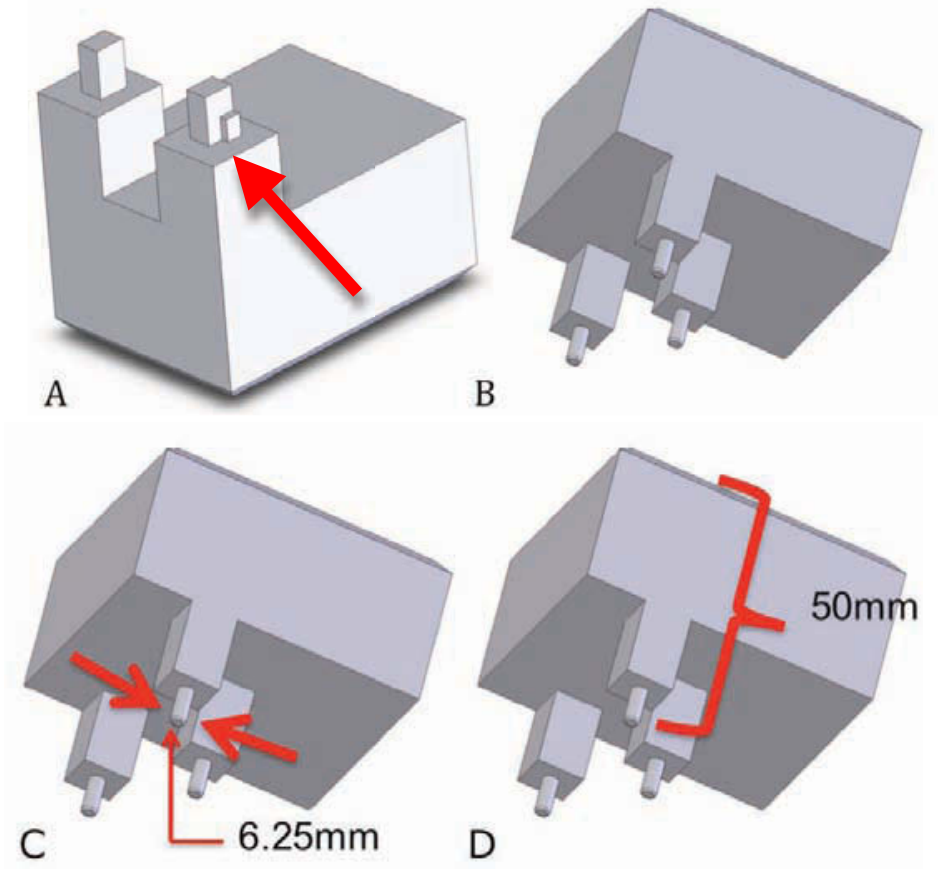

Figure 3-13. Test Gauges.

A. Lower test gauge. B. Upper test gauge. C. The upper test gauge uses a surrogate measurement point that is the external surface of the cylinder (diameter $6.25 \mathrm{~mm}$ ). D. The upper test gauge uses a surrogate measurement point $50 \mathrm{~mm}$ above the center of the inferior border of the cylinder. 


\section{Upper Test Jig}

Upper test gauge measurements utilized surrogate measurement points for all axes. The surrogates were used to facilitate access for measurements without disruption of test gauge position and to simplify the fabrication of the measurement jigs. The surrogate point for the $Z$ axis measured $55 \mathrm{~mm}$ above the target depicted in Figure 3-13. The surrogate points of measurement for the $\mathrm{X}$ and $\mathrm{Y}$ axes was the external surface of the cylinder projecting down from the upper test gauge. The target for the $\mathrm{X}$ and $\mathrm{Y}$ measurement was the center of the cylinder with a radius of $3.12 \mathrm{~mm}$.

\section{Measurement Tools}

All $\mathrm{X}$ and $\mathrm{Y}$ axis measurements were conducted with a 6" digital depth gauge while the height measurements utilized a 10" analog height gauge. Surrogate to target measurements were completed with a 6" digital caliper. Measurement tools are pictured in Figure 3-14.

\section{Articulator Evaluation}

78 unused, Whip Mix 2240Q articulators were evaluated at the Whip Mix Corporation manufacturing facility, immediately following calibration with the Whip Mix Verification Gage. A custom-made measurement table was fabricated for use in evaluating the $\mathrm{X}, \mathrm{Y}$ and $\mathrm{Z}$ axis position of the upper and lower member of the instrument in hinge closure (centric) and excursive movement (eccentric). 81 used, Whip Mix 2240 articulators were evaluated at the University of Tennessee College of Dentistry, utilizing the same protocol as the unused instruments.

\section{Evaluation of Condylar Inclination}

1. Condylar inclination was programmed to "FB" on left and right sides.

2. The incisal pin was raised.

3. The articulator was securely positioned in the jig, with condyle posts in contact with the top plate (Figure 3-7).

4. Attach the 2245 check gauge (Figure 3-9).

5. Check calibration by following manufacturer's instructions.

6. Record calibration status.

7. Drop and lock incisal pin.

8. Zero the digital depth gauge on the measurement jig base (Figure 3-10A).

9. Using a digital angle gauge measure and record left and right condylar inclination (Figure 3-10B).

10. Set condylar inclination to $30.0+/-0.1$ degree.

11. Remove 2245 check gauge. 


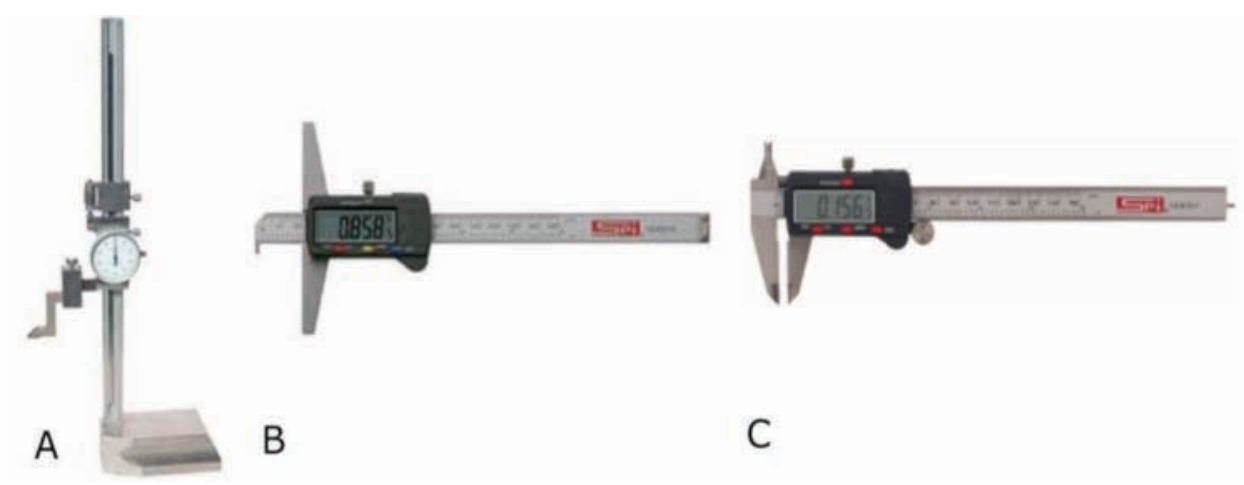

\section{Figure 3-14. Measurement Tools.}

A. Z axis measurements were performed with a 10" Dial Height Gauge (Swiss Precision Instrument Inc., Garden Grove, CA). Scale 0.001”. Reported Accuracy 0.001”. B. X and Y axis measurements were performed with a 6" Digital Depth Gauge (Swiss Precision Instrument Inc., Garden Grove, CA). Scale 0.001”. Reported Accuracy 0.001”. C. 6” Digital Caliper (Swiss Precision Instrument Inc., Garden Grove, CA). Scale 0.001”. Reported Accuracy 0.001 . 


\section{Evaluation of the Lower Check Gauge}

1. Place lower check gauge on the lower member.

2. Measure and record the left and right dimension from the lower check gauge to the $\mathrm{X}$ gauge blocks utilizing the digital depth gauge.

3. Measure and record the left and right dimension from the lower check gauge to the $\mathrm{Y}$ gauge blocks utilizing the digital depth gauge.

4. Measure and record the left and right dimension from the lower check gauge to the base of the measuring jig utilizing the height gauge.

Measurements for the lower check gauge are illustrated in Figure 3-15.

\section{Evaluation of the Upper Check Gauge}

1. Place upper check gauge on the upper member.

2. Engage the centric latch.

3. Measure and record the left and right dimension from the upper test gauge surrogate measurement point to X gauge blocks utilizing the digital depth gauge.

4. Measure and record the left and right dimension from the upper test gauge surrogate measurement point to Y gauge blocks utilizing the digital depth gauge.

5. Measure and record the left and right dimension from the upper test gauge surrogate measurement point to the base of the measuring jig utilizing the height gauge.

Measurements for the upper check gauge are illustrated in Figure 3-16.

\section{Evaluation of the Eccentric Movement}

1. Place the $Z$ Block in the lower check gauge (Figure 3-12, Figure 3-17).

2. Posture the upper member in left eccentric movement.

3. Ensure contact with the upper test gauge (Figure 3-12, Figure 3-17).

4. Secure the position of the upper member with the eccentric pin.

5. Measure and record the dimension from the left test gauge to the $\mathrm{X}$ gauge block utilizing the digital depth gauge. Measure and record the dimension from the left test gauge to the $\mathrm{Y}$ gauge block utilizing the digital depth gauge.

6. Measure and record the dimension from the left test gauge $Z$ surrogate to the measurement jig with the height gauge.

7. Repeat steps 1-5 in right eccentric posture.

Measurements for the lower check gauge are illustrated in Figure 3-17. 


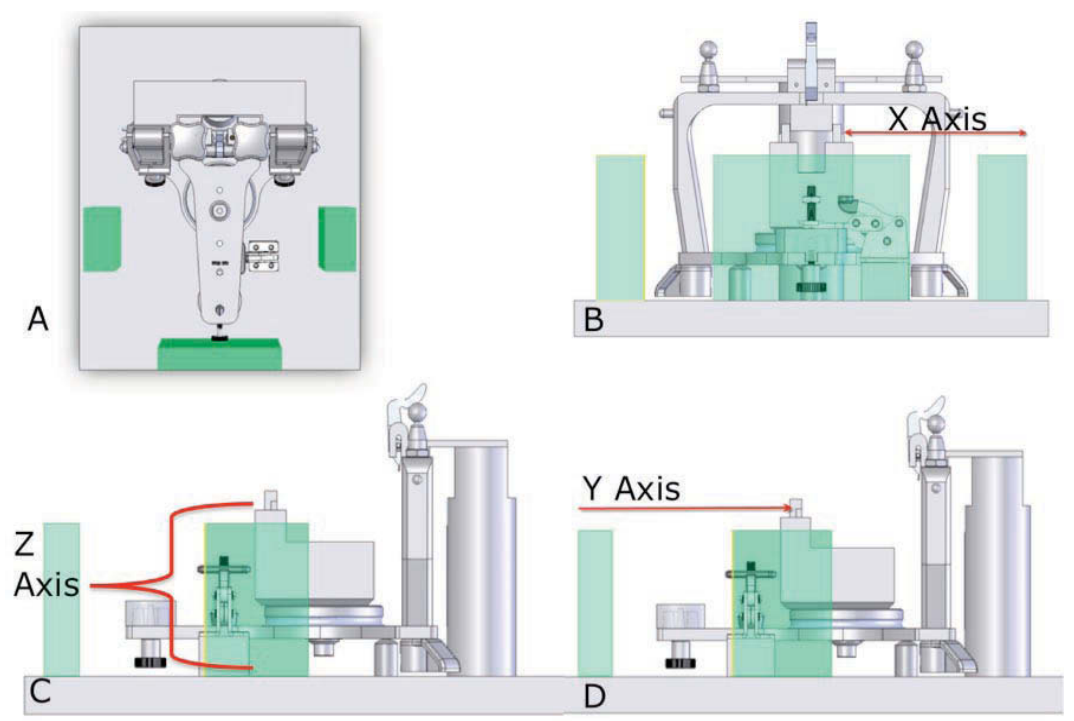

Figure 3-15. Lower Test Gauge $X$ and $Y$ and $Z$ Axis Measurements.

A. Overhead view. B. Lower member $Z$ axis measurement. C. Lower member $Z$ axis measurement. D. Lower member Y axis measurement.

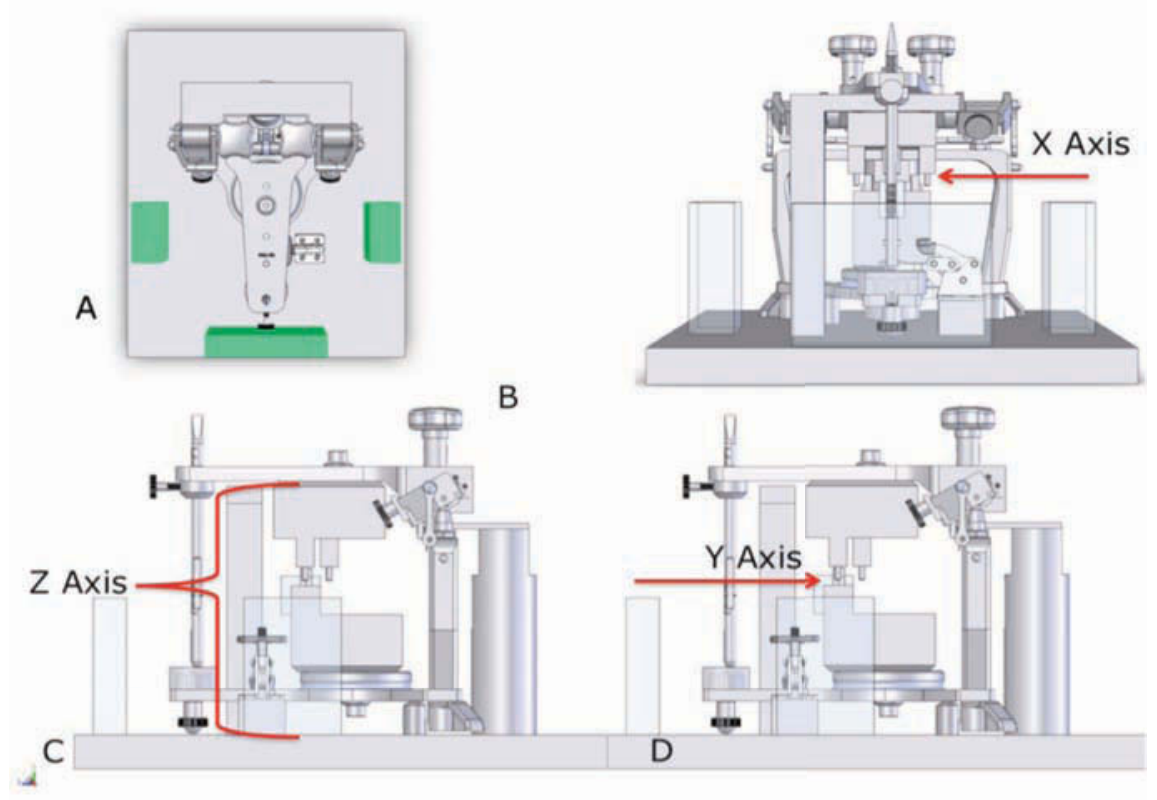

Figure 3-16. Upper Test Gauge $X$ and $Y$ and $Z$ Axis Measurements.

A. Upper member overview. B. Upper member $X$ axis measurement. C. Upper member Z axis measurement. D. Upper member Y axis measurement. 


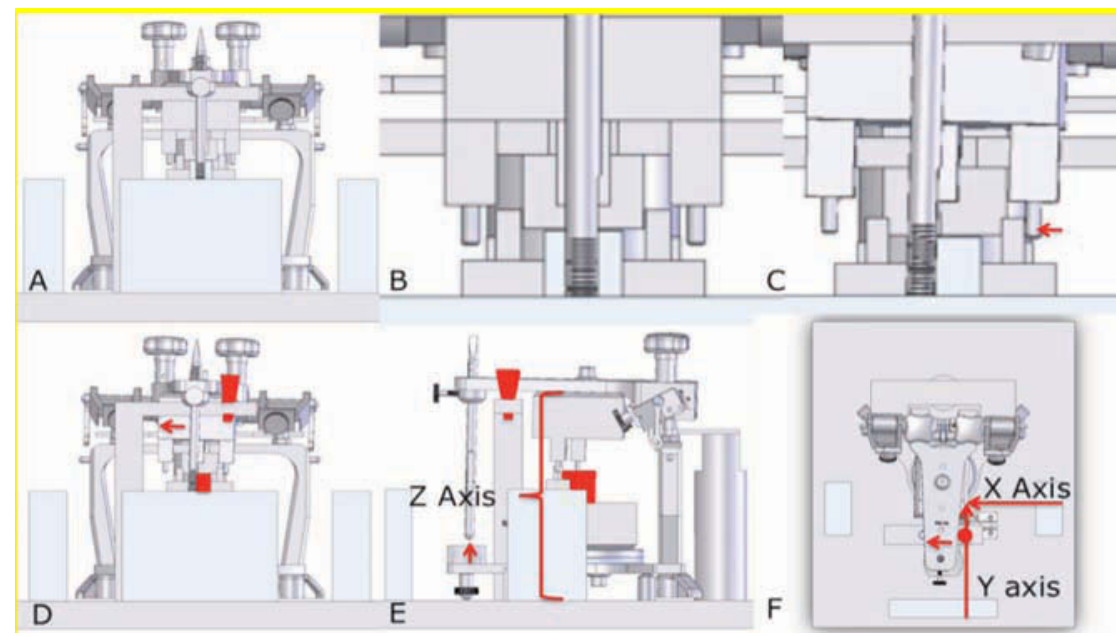

Figure 3-17. Upper Test Gauge Eccentric Measurements.

A. Frontal view in centric closure. B. Close up view of test gauges in centric closure. C. Close up view of test gauges in right eccentric posture. Note: the upper member cylinder is positioned in contact with the lower test gauge. D. Frontal view of right eccentric posture. Note: presence of Eccentric Pin and Block. E. Right lateral view illustrating the $Z$ axis measurement. Note: vertical change in the incisal pin associated with use of the Z Block. F. Overhead view of $\mathrm{X}$ and $\mathrm{Y}$ axis eccentric measurements. 


\title{
CHAPTER 4: RESULTS
}

\author{
Instrument Calibration
}

$100 \%$ of 78 new and $91.8 \%$ of 81 used articulators were confirmed interchangeable with the 2245 check gauge. Non-calibrated instruments were excluded from the remainder of the study. The resultant population of used instruments changed from 80 to 71 test instruments.

\section{Evaluation of Visually Programmed Condylar Inclination}

Visually programmed condylar inclination for all instruments was evaluated on the measurement jig. All articulators were programmed and recorded by the same operator. The values were recorded, analyzed and listed in Table 4-1. With 95\% confidence, New Whip Mix 2240s were programmed with +/- 0.302 degrees of the sample mean. Used articulators were programmed within $+/-0.233$ degrees with the same level of confidence.

\section{Reproducibility of 3D Positioning of the Lower Member within the Measurement Jig}

Lower member positioning within the measurement jig was evaluated in order to determine whether it alone could be used as a baseline for future measurements of eccentric positioning and thereby simplify the measurement protocol.

The lower member on new articulators was positioned within $+/-0.082,+/-0.094$ and $+/-0.175 \mathrm{~mm}$ of each mean at $95 \%$ confidence in the $\mathrm{X}, \mathrm{Y}$ and $\mathrm{Z}$ axes. While used articulators positioned within $+/-0.185,+/-0.141$ and $+/-0.031 \mathrm{~mm}$ in $\mathrm{X}, \mathrm{Y}$ and $\mathrm{Z}$ axes with the same level of confidence.

Calculated data for lower member positioning is located in Table 4-2.

\section{Reproducibility of 3D Positioning of the Upper Member within the Measurement Jig}

The hinge closure positioning of the upper member of the articulator was evaluated as the starting point in the calculation of the spatial change during a prescribed eccentric movement. The upper member of new articulators was positioned within $+/-0.119$, $+/-0.085$ and $+/-0.174 \mathrm{~mm}$ in the X, Y and Z Axes. Used instruments were found positioned with $95 \%$ confidence within $+/-0.116,+/-0.108$ and $+/-0.032 \mathrm{~mm}$ in XY and $\mathrm{Z}$ axes respectively. Calculated data for upper member hinge closure positioning is located in Table 4-3. 
Table 4-1. Condylar Inclination Set by Operator Eye.

\begin{tabular}{lccccc}
\hline & \multicolumn{2}{c}{ New Articulators } & & \multicolumn{2}{c}{ Used Articulators } \\
\cline { 2 - 3 } \cline { 5 - 6 } Condyle & Left & Right & & Left & Right \\
\hline Mean* & 29.632 & 29.887 & & 28.955 & 29.576 \\
95\% Confidence & 0.153 & 0.302 & & 0.233 & 0.159 \\
Interval & & & & 6.6 & 4.0 \\
Range & 3.5 & 4.5 & & & \\
\hline
\end{tabular}

$*$ Units of measurement are presented in degrees.

Table 4-2. Positioning of the Lower Articulator Member within the Measurement Jig.*

\begin{tabular}{lccccccc}
\hline \multicolumn{1}{c}{ Sample } & Statistic & $\begin{array}{c}\mathbf{X} \\
\text { Left }\end{array}$ & $\begin{array}{c}\text { X } \\
\text { Right }\end{array}$ & $\begin{array}{c}\text { Y } \\
\text { Left }\end{array}$ & $\begin{array}{c}\text { Y } \\
\text { Right }\end{array}$ & $\begin{array}{c}\text { Z } \\
\text { Left }\end{array}$ & $\begin{array}{c}\text { Z } \\
\text { Right }\end{array}$ \\
\hline New & $95 \%$ CI $+/-$ & 0.082 & 0.081 & 0.072 & 0.094 & 0.175 & 0.164 \\
Instruments & Range & 3.200 & 2.845 & 2.997 & 4.851 & 4.216 & 4.140 \\
& & & & & & & \\
Used & $95 \%$ CI $+/-$ & 0.185 & 0.155 & 0.141 & 0.132 & 0.024 & 0.031 \\
Instruments & Range & 5.283 & 6.985 & 5.080 & 2.946 & 0.635 & 0.864 \\
\hline
\end{tabular}

*All measurements are presented in millimeters. CI, confidence interval.

Table 4-3. Positioning of the Upper Articulator Member within the Measurement Jig in Hinge Closure.*

\begin{tabular}{lccccccc}
\hline \multicolumn{1}{c}{ Sample } & Statistic & $\begin{array}{c}\text { X } \\
\text { Left }\end{array}$ & $\begin{array}{c}\text { X } \\
\text { Right }\end{array}$ & $\begin{array}{c}\text { Y } \\
\text { Left }\end{array}$ & $\begin{array}{c}\text { Y } \\
\text { Right }\end{array}$ & $\begin{array}{c}\text { Z } \\
\text { Left }\end{array}$ & $\begin{array}{c}\text { Z } \\
\text { Right }\end{array}$ \\
\hline New & $95 \%$ CI $+/-$ & 0.111 & 0.119 & 0.078 & 0.085 & 0.163 & 0.174 \\
Instruments & Range & 3.200 & 3.327 & 3.073 & 3.226 & 3.835 & 5.207 \\
& & & & & & & \\
Used & $95 \%$ CI $+/-$ & 0.069 & 0.116 & 0.097 & 0.108 & 0.030 & 0.032 \\
Instruments & Range & 1.981 & 5.258 & 3.861 & 3.937 & 0.762 & 0.889 \\
\hline
\end{tabular}

*All measurements are presented in millimeters. CI, confidence interval. 


\section{Reproducibility of 3D Positioning of the Upper Member within the Measurement Jig during a Prescribed Eccentric Movement}

The eccentric positioning of the upper member of the articulator was evaluated to compare spatial change from hinge closure position. A single instrument was tested 25 times in order to check the consistency of the eccentric X axis measurement and produced a 95\% confidence interval of $+/-0.012 \mathrm{~mm}$.

The upper member of new articulators were eccentrically positioned within $+/-0.071 \mathrm{~mm}$ to the $\mathrm{Y}$ axis and $+/-0.144 \mathrm{~mm}$ to the $\mathrm{Z}$ axis. Used articulators were positioned within $+/-0.047 \mathrm{~mm}$ and $+/-0.030 \mathrm{~mm}$ in $\mathrm{Y}$ and $\mathrm{Z}$ axis respectively with $95 \%$ confidence. Measurements were also taken in the $\mathrm{Y}$ and $\mathrm{Z}$ axis on the contra-lateral side. The longer radius of rotation would result in an exaggerated change in position of the test gauge. The upper member of used articulators measured contra-laterally was eccentrically positioned on average within $+/-0.079 \mathrm{~mm}$ and $+/-0.080 \mathrm{~mm}$. This additional measurement was added post-evaluation of the new instruments. Calculated data for upper member eccentric positioning is located in Table 4-4.

\section{Net Change in Spatial Position from Hinge Closure of the Upper Member during a Prescribed Eccentric Movement}

The spatial change that occurred during eccentric positioning from hinge closure was calculated from the respective data sets. New articulator change in spatial position measured $+/-0.109$ and $+/-0.187 \mathrm{~mm}$ while used articulators measured within $+/-0.105$ and $+/-0.033 \mathrm{~mm}$. The positional change of the upper member in left eccentric movement on the contra-lateral side was $+/-0.321$ and $+/-0.344 \mathrm{~mm}$ in the $\mathrm{Y}$ and $\mathrm{Z}$ axes. The upper member of new articulators was eccentrically positioned within $+/-0.0125$ and $+/-0.0256$ and used articulators were found positioned within $+/-0.0079$ and $+/-0.0051$ in $\mathrm{Y}$ and $\mathrm{Z}$ axes respectively within $95 \%$ confidence. Measurements were also taken in the $\mathrm{Y}$ and $\mathrm{Z}$ axes on the contra lateral side of the movement. The longer radius of rotation would result in an exaggerated change in position of the test gauge position. The upper member of used articulators measured contra-laterally were eccentrically positioned within $+/-0.344$ and $+/-0.321$. This additional measurement was added following evaluation of the new instruments. Calculated data for upper member eccentric positioning is located in Table 4-5. 
Table 4-4. Eccentric Positioning of the Upper Articulator Member within the Measurement Jig.*

\begin{tabular}{|c|c|c|c|c|c|}
\hline Sample & Statistic & Y Left & Y Right & Z Left & Z Right \\
\hline \multirow[t]{2}{*}{ New Instruments } & $95 \% \mathrm{CI}+/-$ & 0.040 & 0.071 & 0.104 & 0.144 \\
\hline & Range & 0.965 & 3.023 & 4.445 & 4.826 \\
\hline \multirow[t]{2}{*}{ Used Instruments } & $95 \% \mathrm{CI}+/-$ & 0.036 & 0.047 & 0.024 & 0.030 \\
\hline & Range & 0.787 & 1.397 & 0.533 & 0.762 \\
\hline \multirow[t]{2}{*}{ Used Instruments $2 * *$} & $95 \% \mathrm{CI}+/-$ & 0.043 & 0.079 & 0.080 & 0.040 \\
\hline & Range & 0.889 & 2.388 & 2.794 & 1.245 \\
\hline
\end{tabular}

*All measurements are presented in millimeters. ${ }^{*}$ Measurements were taken at the opposite side of the test jig with a longer radius of rotation. CI, confidence interval.

Table 4-5. Average Spatial Change in Prescribed Eccentric Movement.*

\begin{tabular}{|c|c|c|c|c|c|}
\hline Sample & Statistic & Y Left & Y Right & Z Left & Z Right \\
\hline \multirow[t]{2}{*}{ New Instruments } & $95 \% \mathrm{CI}+/-$ & 0.085 & 0.109 & 0.187 & 0.184 \\
\hline & Range & 3.302 & 4.851 & 3.810 & 3.556 \\
\hline \multirow[t]{2}{*}{ Used Instruments } & $95 \% \mathrm{CI}+/-$ & 0.090 & 0.105 & 0.028 & 0.033 \\
\hline & Range & 3.632 & 3.683 & 0.610 & 0.762 \\
\hline \multirow[t]{2}{*}{ Used Instruments $2^{* *}$} & $95 \% \mathrm{CI}+/-$ & 0.156 & 0.321 & 0.344 & 0.188 \\
\hline & Range & 0.991 & 2.489 & 2.667 & 1.473 \\
\hline
\end{tabular}

*All measurements are presented in millimeters. ${ }^{* *}$ Measurements were taken at the opposite side of the test jig with a longer radius of rotation. CI, confidence interval. 


\section{CHAPTER 5: DISCUSSION}

Calibration of articulators involves the control of complex three-dimensional linear and angular relationships of the upper and lower members. Tolerances of manufactured parts and their assembly is under the control of the manufacturer, while programming an articulator is primarily under the control of the dentist and technician. The combination of these two factors determine if the dentist and a remote technician are able to see the same patient replication when interchanging casts on different instruments.

The ability of a manufacturer to produce a semi-adjustable articulator that can be considered interchangeable has been evaluated (Cowan et al. 1991; Kitzis et al. 1991; Unger et al. 1991; Sanchez et al. 1993; Price and Mansfeild 1999; Chung et al. 2001; Dexter et al. 2001; Hatzi et al. 2001; Price et al. 2001). The published maximum level of tolerable error in articulators claiming interchangeability is $0.166 \mathrm{~mm}$ vertically and $0.102 \mathrm{~mm}$ horizontally when testing the Hanau Wide Vue (Chung et al. 2001). The series of articles by Price (Price and Mansfeild, 1999; Price et al. 2000; Price et al. 2001) claim interchangeability for the Whip Mix 2240 at less than $0.052 \mathrm{~mm}$ vertically and less than $0.094 \mathrm{~mm}$ horizontally. These studies are the closest comparables to the current study as they use the same instrument and have good sample size. The level of horizontal and vertical tolerance in published studies on interchangeability is summarized in Table 5-1.

The Whip Mix 2240 articulator was chosen as the subject of this investigation due to its claim of interchangeability, history of hinge axis interchangeability studies, availability of instruments, and manufacturer support. Following fabrication of the test jig, 78 new instruments were assessed at Whip Mix Corp. (Louisville, KY) immediately following calibration.

The device used to verify calibration for the Whip Mix 2240 articulator attaches to the upper and lower members and carries precision machined matching surfaces of a column. Calibration is then assessed by sliding an oversized ring over the seam. Calibration is verified in a pass-fail assessment when there is no catch when the $94 \mu \mathrm{m}$ oversized ring passes freely with centric latch engages and without additional force being added to the system (Price and Mansfield, 1999).

The results of this study cannot be directly compared to the reference studies due to a change in measurement system. This experiment operated with the assumption that the calibrated instruments will present a hinge closure tolerance similar to that previously reported. The current study was not primarily concerned with the calibration of individual instruments, rather as a pilot study to assess generalized calibration of a large sample of instruments. All instruments passed testing with the 2245 Check Gauge, the range and confidence intervals produced were therefore reflective of a calibrated instrument within this measurement jig. Maximum confidence intervals for the new instruments were $+/-0.12 \mathrm{~mm}$ horizontally and $+/-0.18 \mathrm{~mm}$ vertically. Used instruments produced confidence intervals of $+/-0.12 \mathrm{~mm}$ and $+/-0.04 \mathrm{~mm}$ vertically. No explanation is known for the larger than expected confidence interval for the new instruments in hinge closure, though it is hypothesized that operator experience with the measurement jig and dial height gauge may 
Table 5-1. Interchangeability Studies and Quantified Error in Hinge Closure.

\begin{tabular}{|c|c|c|c|c|c|}
\hline Author & Instrument & $\begin{array}{c}\text { Inter- } \\
\text { changeable } \\
\mathrm{Y} / \mathrm{N} \\
\end{array}$ & $\begin{array}{c}\text { Quantified } \\
\text { Vertical } \\
\text { Error }\end{array}$ & $\begin{array}{c}\text { Quantified } \\
\text { Horizontal } \\
\text { Error } \\
\end{array}$ & Sample Size \\
\hline $\begin{array}{l}\text { Unger } \\
\text { Ung }\end{array}$ & $\begin{array}{c}\text { Dentatus } \\
\text { ARL }\end{array}$ & Suspect & Shimstock & No & 8 \\
\hline Kitzis & Denar & Yes & No & No & 12 \\
\hline Cowan & $\begin{array}{l}\text { Whip Mix } \\
2240\end{array}$ & Yes & $0.013 \mathrm{~mm}$ & $0.08 \mathrm{~mm}$ & 8 \\
\hline Sanchez & $\begin{array}{l}\text { Hanau } \\
\text { Modular }\end{array}$ & Yes & $0.038 \mathrm{~mm}$ & $0.29 \mathrm{~mm}$ & 8 \\
\hline Price & $\begin{array}{l}\text { Whip Mix } \\
2240\end{array}$ & Yes $83 \%$ & $\begin{array}{c}0.026<\mathrm{X} \\
<0.052 \mathrm{~mm}\end{array}$ & $0.094 \mathrm{~mm}$ & 46 \\
\hline \multirow[t]{2}{*}{ Price } & $\begin{array}{l}\text { Whip Mix } \\
2240\end{array}$ & Yes $89.5 \%$ & $>0.052 \mathrm{~mm}$ & $0.094 \mathrm{~mm}$ & 38 \\
\hline & Whip Mix & Yes 94\% & $>0.052 \mathrm{~mm}$ & $0.094 \mathrm{~mm}$ & 71 \\
\hline Chung & $\begin{array}{c}\text { Hanau Wide } \\
\text { Vue }\end{array}$ & Yes & $0.166 \mathrm{~mm}$ & $0.102 \mathrm{~mm}$ & 30 \\
\hline Hatzi & $\begin{array}{c}\text { Kavo Protar } \\
\text { Artex AL } \\
\text { Whip Mix } \\
3040\end{array}$ & $\begin{array}{l}\mathrm{No} \\
\mathrm{No} \\
\mathrm{No}\end{array}$ & $\begin{array}{l}\text { No } \\
\text { No } \\
\text { No }\end{array}$ & $\begin{array}{l}\text { No } \\
\text { No } \\
\text { No }\end{array}$ & $\begin{array}{l}5 \\
5 \\
5\end{array}$ \\
\hline
\end{tabular}


have contributed to more consistent measurements in the used sample that followed evaluation of the new instruments.

Studies of accuracy of face-bow and ear-bow approximations of the hinge axis typically reference a $6 \mathrm{~mm}$ radius (Teteruck and Lundeen 1966; Palik et al. 1995). Using this approximation, Weinberg calculated a $0.2 \mathrm{~mm}$ occlusal error inherent to this common clinical procedure (Weinberg, 1963). This value has been cited as a reference for clinical acceptability for articulation in general practice although the formula was incompletely defined and therefore impossible to confirm (Wachtel and Curtis, 1987).

The ability of one operator to program an instrument to a pre-determined condylar inclination was also assessed in this study. Results indicate that with 95\% confidence instruments could be reliably programmed, by eye, to within one degree. The level of condylar programming is clinically acceptable, though the ability of different operators to set the instrument is likely a more clinically applicable study. The impact of condylar inclination accuracy is geometrically unlikely to effect hinge closure, yet it will have a more influence in any condylar movement other than pure rotation about the hinge axis. Less than one degree of error is not expected to produce significant occlusal error as it would be a small component within a system that utilizes an approximation of the hinge axis and fixed intercondylar width.

Movement from hinge closure has not been studied in terms of calibration or interchangeability. In an effort to produce accurate diagnostics and precise restorations, this parameter is important to dental treatment. Not only is precise occlusal contact an important feature, the absence of potentially damaging contact may be equally as important (Schuyler 1953; William H. McHorris, personal communication, September 2009).

Though data presented in previous studies make it appear acceptable to utilize interchangeability in the $\mathrm{Y}$ axis. When analysis continues past the saggital plane, the horizontal plane raises concern. The greatest error is reported to occur in semi-adjustable articulators in the horizontal plane (Curtis and Wachtel 1987; Wachtel and Curtis 1987). Y axis has been shown in both new and used this study to have a 95\% confidence interval of $+/-0.11 \mathrm{~mm}$, which is interpreted such that an instrument from this sample would likely position the instrument eccentrically in the same position within $0.22 \mathrm{~mm}$. The $\mathrm{X}$ axis was controlled in this experiment and produced a $95 \%$ confidence interval of $+/-0.012 \mathrm{~mm}$. The $\mathrm{Z}$ axis confidence interval for new and used instruments was $+/-0.18 \mathrm{~mm}$ and $+/-0.03 \mathrm{~mm}$. Similar to the hinge axis measurements the increased confidence interval for the new instruments is hypothesized to be the result of operator familiarity with the measurement jig the height gauge. If an instrument on either end of the confidence interval were to be employed interchangeably, there is potential for clinically significant positive and negative occlusal error. Since these errors do not exist clinically in one plane no inference as to the location of the error is practical.

In 2010 Whip Mix employed a new Verification Gage replacing the 2245 Check Gauge. The design has broadened the mating surfaces and is expected to improve hinge axis calibration. Assessment protocol evaluates vertical tolerance at four line angles via frictional resistance to removal of the shimstock. Two gauge pins widely spaced apart must also freely pass through aligned holes in the upper and lower member to test the $Z$ axis calibration, an 
element not controlled with the 2245 check gauge (Whip Mix 2010). All new articulators evaluated with the 2245 check gauge following verification on the new gauge passed the test. This system is expected to increase the horizontal, vertical and rotational calibration of the Whip Mix instruments. All new instruments, but none of the used tested were calibrated with the new Verification Gage in the factory. The results of this investigation did not yield a measured benefit to the new system.

The manufacturer in addition to Price (Price and Mansfield 1999; Price et al. 2000; Price et al. 2001) emphasizes the need for thorough cleaning of the condylar housings. All new articulators passed tests of calibration and were free of such confounding variables. Of the used articulators tested none were free of confounding variables, the method of cleaning was visual and mechanical and several of the instruments with lack of calibration status had gross adherent debris, which did not readily allow for cleaning during the assessment window. A potential source of error could have been removed with thorough cleaning.

Average XYZ measurements with the novel measurement jig display confidence intervals well outside the $0.094 \mathrm{~mm}$ horizontal tolerance at $+/-0.12 \mathrm{~mm}$ and $0.052 \mathrm{~mm}$ vertical tolerance at +/- 0.18mm (Cowan 1991; Price and Mansfield 1999; Price et al. 2001). The change in measurement system makes comparison between measurement systems difficult as is the comparison between graded leaves of shimstock and gauge measurement or comparing a fixed measurement with a confidence interval. Regardless, the results of this study carry greater range for calibration than those reported in the previous studies.

Eccentric positioning produced nearly the same confidence intervals for each sample of instruments when compared to hinge closure. This concordance of data suggests that overall the instruments produce similar changes in position from hinge closure to eccentric position. This study does not, however, imply that each instrument is interchangeable in eccentric positions as instruments calibrated at opposite ends of the confidence interval may in fact carry clinically significant differences.

The variability found may represent manufacturing error, operator error in data collection, transcription errors and inappropriate measurement system. The range of data collected in this comparatively large sample lends a degree of suspicion to this method of measurement. Operator familiarity and practice may have been a source of increased range in data collected for the new instruments. If gauge blocks had been positioned closer to the articulator and test gauges, a more accurate, precise and repeatable measurement may have resulted. The novel measurement jig requires a 3-4" manually positioned measurement from a depth gauge to the gauge blocks. With long radius and small scale of the measured difference, range in measurement values can increase with relatively small changes in depth gauge angulation, where a narrowed measurement jig and gauge block would likely yield a more accurate result.

Clinical concern still remains for use of semi-adjustable articulation interchangeably where precise contacts or precise lack of interocclusal contacts are required and the operator is left to choose if the convenience of interchangeability outweighs precision in restoration. 


\section{CHAPTER 6: CONCLUSIONS}

The results of this study suggest that:

- A single operator can program the horizontal condylar inclination of the Whip Mix 2240 reliably within one degree.

- A prescribed lateral movement on a series of new and used articulators reliably positioned a specific measurement point to the same level of tolerance found in hinge closure of the same instrument.

- $88.5 \%$ of 1 year-old articulators verified as interchangeable with the 2245 check gauge.

- A calibrated articulator eccentrically positioned the test gauge within $+/-0.2 \mathrm{~mm}$ vertically and $+/-0.1 \mathrm{~mm}$ horizontally with $95 \%$ confidence. 


\section{CHAPTER 7: LIMITATIONS AND FUTURE DIRECTIONS}

Though a large number of articulators and measurements were acquired for this investigation the measurement jig was unable to be trialed prior to implementation of the test protocol. The result of the lack of trial run likely produced sub-optimal results. Given sufficient time to test the jig and propose modification prior to data collection, the results may have carried more weight.

Although fabricated from precision stock metal, the measurement jig design proved to place gauge blocks at too great a distance to optimally measure the small scale of changes required by this system.

The most accurate assessment of the articulator's calibration and accuracy result from clean instruments, without gypsum, wax or other debris attached to either mounting surface, condyle or condylar housing. Future investigations should ensure a mechanism to clean used instruments thoroughly prior to evaluation.

Re-engineering of gauge block position and possible use of a cam-activated mechanism to produce and limit lateral excursion without the possibility of slippage could improve the existing protocol.

The use of a coordinate measuring system would allow for highly accurate measurements in this area.

Multiple operators would not only corroborate measurements, it would reproduce the clinical reality employed in articulator interchangeability during transfer of casts from the dentist to the laboratory. 


\section{LIST OF REFERENCES}

Beck, H.O. (1959). A Clinical Evaluation of the Arcon Concept of Articulation. Journal of Prosthetic Dentistry, 9:409-421.

Berstrom, G. (1950). On the Reproduction of Dental Articulation by Means of Articulators. Acta Odontologica Scandanavica Supplement, 9:3-149.

Bonwill, W.G.A. (1899). The Scientific Articulation of the Human Teeth as Founded on Geometrical, Mathematical, and Mechanical Laws. Dental Items of Interest, 21:617-643.

Chou, T.M., Pameijer, C.H. (1987). An Investigation of the Reproducibility of Articulators. Journal of Prosthetic Dentistry, 58:442-448.

Chung, C.C., Chai, J., Jameson, L.M. (2001). Interchangeability of a Semi-Adjustable Articulator. International Journal of Prosthodontics, 14:427-431.

Clark, D.M., Oyen, O.J., Feil, P. (2001). The Use of Specific Dental School-Taught Restorative Techniques by Practicing Clinicians. Journal of Dental Education, 65:760-765.

Clark, G.T., Tsukiyana, Y., Baba, K., Wantanabe, T. (1999). Sixty-Eight Years of Experimental Occlusal Interference Studies: What Have We Learned? Journal of Prosthetic Dentistry, 82:704-713.

Costen, J.B. (1934). A Syndrome of Ear and Sinus Symptoms Dependent upon Disturbed Function of the Temporomandibular Joint. Annals of Otology, Rhinology and Laryngology, 43:1-15.

Cowan, R.D., Sanchez, R.A., Chappell, R.P., Glaros, A.G., Hayden, W.J. (1991). Verifying the Reliability of Interchanging Casts with Semi-Adjustable Articulators. International Journal of Prosthodontics, 4:258-264.

Curtis, D.A., Wachtel, H.C. (1987). Limitations of Semi-Adjustable Articulators. Part II: Straight Line Articulators with Provision for Immediate Side. Journal of Prosthetic Dentistry, 58:569-573.

Dexter, W.S., Moore, D.J., Boardman, T.J. (2001). Assessing the Interchangeability of the Hanau Wide-Vue Semi-Adjustable Articulator. General Dentistry, 49:516-520.

Girrbach Artex, Frequently Asked Questions. http://www.jensendental.com/artex/facebow/art_faq.htm\#best., Accessed 04/23/2011.

Glossary of Prosthodontic Terms. (2005). Journal of Prosthetic Dentistry, 94:10-92. 
Hatzi, P., Milltein, P. Maya, A. (2001). Determining the Accuracy of Articulator Interchangeability and Hinge Axis Reproducibility. Journal of Prosthetic Dentistry, 85:236-245.

Hobo, S., Shillingburg, H.T., Whitsett, L.D. (1976). Articulator Selection for Restorative Dentistry. Journal of Prosthetic Dentistry, 36:35-43.

Ivoclar., http://www.ivoclarvivadent.com/zooluwebsite/media/document/4051/ Stratos $+100+200+300$, Accessed 04/23/2011.

Kitzis, G.D., Millstein, P.L., Nathanson, D. (1991). Determining the Accuracy of Articulator Interchangeability. Journal of Prosthetic Dentistry, 65:845-848.

Kornfeld, M. (1974). Diagnosis and Treatment Planning. In: Mouth Rehabilitation Clinical and Laboratory Procedures. Volume 2. Mosby, St. Louis, pp. 21-100.

Lauritzen, A.G., Bodnar, G.H. (1961).Variations in Location of Arbitrary and True Axis Points. Journal of Prosthetic Dentistry, 11:224-229.

Palik, J.F., Nelson, D.R., White, J.T. (1985). Accuracy of an Earpiece Facebow. Journal of Prosthetic Dentistry, 52:800-804.

Panadent Articulator Advantages. http://www.panadent.com/Catalog/ Educational_Materials/Advantages_of_Panadent_Articul/advantages_of_panadent_ articul.html., Accessed 23/04/2011.

Petropolous, V.C., Weintraub, A.,Weintraub, G.S. (1988). Predoctoral Fixed Prosthodontics Curriculum Survey. Journal of Prosthodontics, 7:183-191.

Pieslingher, E., Bauer, W., Schmiedmayer, H.B. (1995). Computer Simulation of Occlusal Discrepancies Resulting from Different Mounting Techniques. Journal of Prosthetic Dentistry, 74:279-283.

Pilhstrom, B.L., Anderson, K.A., Aeppli, D., Schaffer, E.M. (1986). Association between Signs of Trauma from Occlusion and Periodontitis. Journal of Periodontology, 57:1-6.

Price, R.B., Gerrow, J.D., Loney, R.W., Andreou, P. (2001). Interchangeability of Two SemiAdjustable Articulators. International Journal Prosthodontics, 14(3):255-259.

Price, R.B., Loney, R.W., Andreou, P. (2000). Interchangeability of Semi-Adjustable Articulators after 2 to 7 Years of Use. Journal of Prosthodontics, 9:142-147. 
Price, R.B., Mansfield, W.M. (1999). Long-Term Reliability of Semi-Adjustable Articulator Interchangeability. Journal of Prosthodontics, 8:235-239.

Sanchez, R.A., Moore, D.J., Cowan, R.D., Spencer, P. (1993). Verifying the Reliability of Interchanging Casts between Hanau Modular Articulators. Journal of Prosthodontics, 4:220-223.

Schallhorn, R.G. (1957). A Study of the Arbitrary Center and the Kinematic Center of Rotation for Face-Bow Mountings. Journal of Prosthetic Dentistry, 7:162-169.

Schuyler, C.H. (1953). Factors of Occlusion Applicable to Restorative Dentistry. Journal of Prosthetic Dentistry, 3:772-778.

Shillingburg, H.T., Hobo, S., Whitsett, L.D., Brackett, S.E. (1997). Articulators. In Fundamentals of Fixed Prosthodontics, Quintessence, Chicago, p.73.

Simpson, J.W., Hesby, R.A., Pfeifer, D.L., Pelleu, G.B.Jr. (1984). Arbitrary Mandibular Hinge Axis Locations. Journal of Prosthetic Dentistry, 51:819-822.

Stuart, C.E. (1959). Accuracy in Measuring Functional Dimensions and Relations in Oral Prosthesis. Journal of Prosthetic Dentistry, 9:237-239.

Tamaki, K., Celar, A.G., Beyrer, S., Aoki, H. (1997). Reproduction of Excursive Tooth Contact in an Articulator with Computerized Axiography Data. Journal of Prosthetic Dentistry, 78:373-378.

Taylor, T.D., Aquilino, S.A., Jordan R.D. (1985). Prosthodontic Laboratory and Curriculum Survey. Part IV: Fixed Prosthodontic Curriculum Survey. Journal of Prosthetic Dentistry, 53:267-270.

Teteruck, W.R., Lundeen B.A. (1966). The Accuracy of an Ear Face-Bow. Journal of Prosthetic Dentistry, 16:1039-1045.

Unger, J.W., Hoffmann, R.M., Diener R.M. (1991). Analysis of the Interchangeability of a Dental Articulator. Journal of Prosthetic Dentistry, 66:813-815.

Wachtel, H.C., Curtis, D.A. (1987). Limitations of Semi-Adjustable Articulators. Part I: Straight Line Articulators without Setting for Immediate Side Shift. Journal of Prosthetic Dentistry, 58:438-442.

Weinberg, L.A. (1959). The Transverse Hinge Axis: Real or Imaginary. Journal of Prosthetic Dentistry, 9:775-787. 
Weinberg, L.A. (1963). An Evaluation of Basic Articulators and Their Concepts. Part II: Arbitrary, Positional, Semi-Adjustable Articulators. Journal of Prosthetic Dentistry, 13:645-663.

Whip Mix Corporation, Articulator Frequently Asked Questions. http://whipmix.com/ wp-content/uploads/via-product-catalog/product_docs/faq_final2_9.pdf., Accessed 04/23/2011.

Wilkie, N.D. (1979). The Anterior Point of Reference. Journal of Prosthetic Dentistry, 41:488-496.

Zuckerman, G.R. (1982). The Geometry of the Arbitrary Hinge Axis as It Relates to the Occlusion. Journal of Prosthetic Dentistry, 48:725-733. 


\section{VITA}

Dr. Mark Hopkins was born in 1977. He received a B.Sc. honours degree in Microbiology and Immunology in 1999 an Advanced Certificate in Anatomy and Cell Biology in 2000 and received his doctoral degree in dentistry (Doctor of Dental Medicine) from the University of Saskatchewan College of Dentistry, Saskatoon, Canada, in 2004. Following service with the Canadian Forces Dental Service he was accepted into the Advanced Prosthodontics Program at University of Tennessee Health Science Center in 2008. Dr. Hopkins is currently a third year resident, specializing in implant, esthetic and reconstructive dentistry at UTHSC. He will be finishing his Master of Dental Science degree from the University of Tennessee. He is a current member of the American College of Prosthodontists, the Canadian Dental Association, the Canadian Association of Prosthodontists, the British Columbia Dental Assocation and the Academy of Osseointegration. Dr. Hopkins will enter private prosthodontic practice in Canada upon completion of his studies. 